\title{
VIDA HUMANA, MUERTE Y SOBREVIVENCIA \\ LA ÉTICA MATERIAL EN LA OBRA DE ENRIQUE DUSSEL
}

Gabriel Herrera Salazar 


\section{VIDA HUMANA, MUERTE Y SOBREVIVENCIA. LA ÉTICA MATERIAL EN LA OBRA DE ENRIQUE DUSSEL}

$$
\text { apuntes def sur: }
$$





\section{VIDA HUMANA, MUERTE Y SOBREVIVENCIA. LA ÉTICA MATERIAL EN LA OBRA DE ENRIQUE DUSSEL}

Gabriel Herrera Salazar

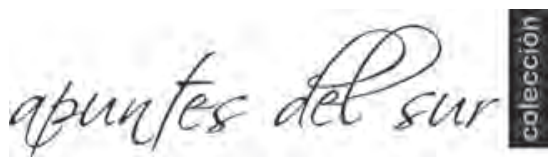

2

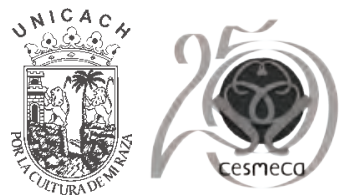




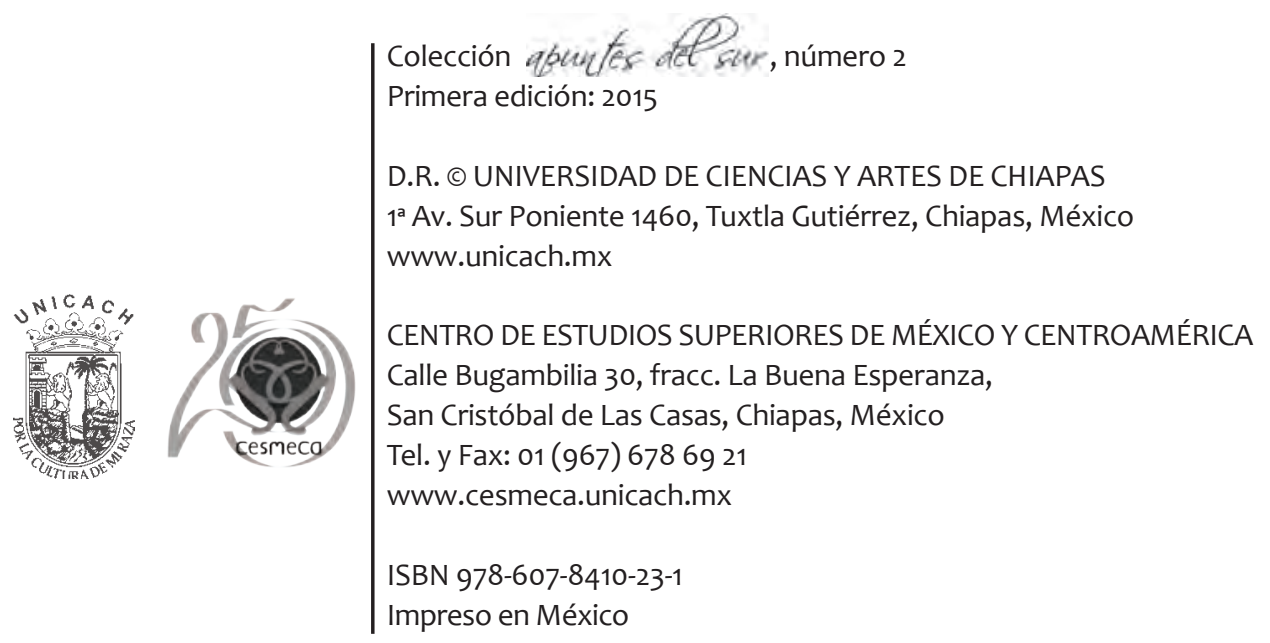


A mis padres:

Gabriel Herrera y Lourdes Salazar

A Enrique Dussel, con admiración 



\section{Índice}

$\begin{array}{lr}\text { Prólogo } & 9\end{array}$

$\begin{array}{ll}\text { Introducción } & 11\end{array}$

Principio material de la ética $\quad 17$

$\begin{array}{ll}\text { La ética formal aristotélica } & 17\end{array}$

La ética formal kantiana $\quad 21$

La propuesta ética material de Enrique Dussel 29

La concepción de la vida

La evolución creadora de la vida en la filosofía

de Henri Bergson $\quad 36$

El principio de responsabilidad de Hans Jonas 44

La vida negada en Enrique Dussel $\quad 48$

Negación material de la vida humana, muerte de la víctima. Punto de partida radical de la ética de la liberación 54

De la ética de la liberación a la política de la liberación 54

El principio crítico-democrático

La política subsumida en la ética $\quad 56$

La vida humana, la muerte y la sobrevivencia 58

Referencias bibliográficas 



\section{PRÓLOGO}

El presente trabajo es relevante para todos aquellos que se inician en la filosofía de la liberación, científicos sociales críticos que parten de fundamentos éticos y luchadores sociales que en sus actos de habla llevan implícita la praxis de la liberación. Puede considerarse como un paso previo a mi obra publicada en 1998 bajo el título: Ética de la liberación en la edad de la globalización y la exclusión, la cual en el 2013 se publicó por primera vez traducida al inglés, lo que hace que su lectura, discusión y crítica lleguen a nuevos rincones del mundo.

Para nosotros, la afirmación de la vida es el contenido de todos los actos humanos y el fin último de la existencia humana; esta es la diferencia que existe con el actual sistema capitalista, el cual tiene como fin último el aumento de la tasa de ganancia. El mal consiste en la perversidad del sistema actual, que ha llevado a poner en crisis la vida de todas las especies que habitamos en el planeta Tierra. Un sistema que produce muerte es injusto y debe éticamente ser cambiado por otro diferente y más equitativo. La liberación se juega en el límite de la vida, en la sobrevivencia del oprimido, el excluido, la víctima. Es por ello que el criterio material de la ética de la liberación es la vida humana.

En diciembre del 2007 en el CIDECI-Universidad de la Tierra, don Durito de la Lacandona —en voz del subcomandante insurgente Marcos- nos dijo: "Cuando parece que no queda nada, quedan los principios". La ética de la liberación es una ética de principios, principios que están inspirados en la digna lucha del EZLN.

El escrito que el lector tiene en sus manos es el resumen de los apuntes de Gabriel Herrera, un alumno que siguió mis cursos desde el año 2000, cuando era estudiante en la carrera de filosofía en la Universidad Autónoma MetropolitanaIztapalapa. Ofrece una guía teórica-pedagógica que sitúa la argumentación filosófica de una ética material crítica fundamentada en seis principios, y en 
pocas páginas logra digerir un trabajo que está expuesto en más de seiscientas. Esperamos que el análisis de esta obra contribuya al diálogo intercultural en el marco del intercambio sobre ética y política frente al despojo.

Enrique Dussel

Profesor emérito de la Universidad Autónoma Metropolitana México

Junio de 2014

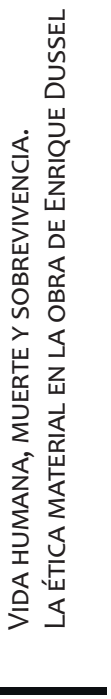

10 


\section{INTRODUCCIÓN}

Hasta el día de hoy, 18 de enero de 1994, sólo hemos tenido conocimiento de la formalización del "perdón" que ofrece el gobierno federal a nuestras fuerzas. ¿De qué tenemos que pedir perdón? ¿De qué nos van a perdonar? ¿De no morirnos de hambre? ¿De no callarnos en nuestra miseria? ¿De no haber aceptado humildemente la gigantesca carga histórica de desprecio y abandono? ¿De habernos levantado en armas cuando encontramos todos los otros caminos cerrados? ¿De no habernos atenido al Código Penal de Chiapas, el más absurdo $y$ represivo del que se tenga memoria? ¿De haber demostrado al resto del país y al mundo entero que la dignidad humana vive aún y está en sus habitantes más empobrecidos?

Subcomandante insurgente Marcos

En el año 2000, en la ciudad de México, los estudiantes de la Universidad Nacional Autónoma de México sostenían una huelga que había comenzado el 20 de abril de 1999; los integrantes de lo que restaba del consejo general de huelga fueron detenidos en una inaceptable cacería de brujas. El 6 de febrero de 2000, la Policía Federal Preventiva tomó Ciudad Universitaria y llevó a cabo arrestos masivos. En aquel trimestre, en las aulas más grandes del edificio B de la Universidad Autónoma Metropolitana-Iztapalapa, el profesor Enrique Dussel impartía 
clases con los salones llenos de estudiantes revolucionarios decepcionados, desesperanzados e insatisfechos. Es en este contexto donde se fue forjando un movimiento de crítica radical entre algunos estudiantes de filosofía, entre quienes se encontraban Jorge Morgado, Paola Rochon, Mario Martínez, Félix Santoyo, Elery Hernández, Luis Otoniel, Agustín Camacho, Jorge García, Ruth Méndez y Thalía Reza, junto con quienes inicié la experimentación en el camino de la filosofía y la anti-filosofía.

Reunidos en el departamento de Luis Otoniel, leíamos —entre cigarros, cervezas y música - a Hegel, Kierkegaard, Marx, Nietzsche, Heidegger, Sartre, Cioran, Derrida, Vattimo, Lyotard, Sabato y Dussel, filosofía y poesía maldita. Había días que nos quedábamos sin comer por falta de dinero; fueron el hambre y la sed los que me hicieron entender el carácter fuerte del principio material de la ética de la liberación de Dussel.

En la búsqueda de recursos para continuar mis estudios, una organización no gubernamental me ofreció una beca de setecientos pesos a cambio de realizar trabajo comunitario de medio tiempo. Es allí donde descubrí más a fondo la filosofía de la liberación, la teología de la liberación y la educación popular. Fuera de las aulas, comprendía qué tan lejos están los textos escritos de la realidad. Como representante de aquella asociación civil, viajé a Chiapas con un grupo de promotores para inaugurar una escuela y conocer el trabajo comunitario en aquella región. Salimos de Ocosingo en camioneta, desde donde viajamos siete horas en carretera y otras siete a pie en medio de la selva. Cuando llegamos a la comunidad, la primera persona que salió a nuestro encuentro, a recibirnos en la proximidad, fue una niña de unos siete años, con un rifle en la mano...

Este suceso marcó en mi vida la experiencia metafísica del rostro del Otro, del pobre, del sujeto metafísico antropológico, de la "víctima". Comprendí de golpe el principio crítico-material de la ética de la liberación, y descubrí el alto contenido material, la coherencia y la lógica de la metafísica dusseliana, así como la pertinencia y la vigencia de la ética de la liberación.

Este trabajo lo titulé Vida humana, muerte y sobrevivencia. La ética material en la obra de Enrique Dussel por consejo del doctor Pedro Enrique García. El objetivo consiste en analizar, situar y explicar indicativamente el concepto de vida humana, contrastándolo con la concepción de la muerte como negación de la vida, además de la sobrevivencia de las víctimas como problema moral y normativo en la propuesta filosófica de Enrique Dussel. 
Este trabajo está dividido en dos partes: una primera en la que realizo un estudio comparativo de la ética de Aristóteles y Kant, al que añado la propuesta ética material de Dussel, y una segunda que incluye los capítulos dos y tres, en los que estudio el contenido material de la ética dusseliana, es decir, la vida humana como corporalidad viviente, y comparo la concepción de vida en Henri Bergson, Hans Jonas y Enrique Dussel.

En la primera parte me ocupo del primero de los seis principios de que consta la ética de la liberación. En este apartado intento situar y explicar los fundamentos que sostienen a las éticas formales, para mostrar que éstas no llegan a la complejidad de la concreción de una ética material porque los supuestos y principios en los que descansan desprecian la carnalidad del cuerpo, o bien divinizan las leyes tratando de hacerlas eternas, fetichizando el Estado y la política, o dejando fuera y sin participación a comunidades marginales — distintas cultural y geográficamente- que sufren las consecuencias no intencionales del egocentrismo y que quedan excluidas en su carnalidad, como víctimas al borde de la muerte. Con lo anteriormente expuesto, presento la ética de la liberación por su principio material, justificando la vida con pretensión de universalidad, dando un paso adelante de las éticas formales y haciendo surgir problemas antes no estudiados.

Una vez situada la problemática de la primera parte, la segunda asciende de los principios abstractos a terrenos más concretos y complejos. En ésta, arranco de la concepción de la vida humana encarnada. El cuarto principio de los seis de la ética de la liberación ahora toma su mayor importancia: es el principio ético crítico el que tratará de compararse con la concepción de la vida evolutiva de Henri Bergson y la angustiosa mortalidad de la vida en el principio de responsabilidad de Hans Jonas. Esta sección es la más importante en este trabajo ya que, de las dos partes de la ética de la liberación de Dussel, la segunda es la que exhibe lo fundamental de la filosofía de la liberación: la vida humana de la "víctima", la que sufre las consecuencias perversas de un sistema de eticidad hegemónico vigente. La negación de la vida de las víctimas humanas - la muerte- es nuestro tema, el asesinato de los que claman por la justicia, de aquellos que critican los sistemas de dominación. Es por la lucha de este sector excluido que el presente trabajo toma con mayor seriedad la real problemática de los frentes de liberación que, al borde de la muerte, claman por la vida, entregándose a la responsabilidad de la sobrevivencia de las víctimas y llegando a dar hasta la vida en sacrificio por la "dignidad" de los 
más pobres y de los más hambrientos de justicia. En la segunda parte de la ética de la liberación, las víctimas humanas padecen el contenido material de la ética, el dolor y la muerte de los más desprotegidos, lo que hace de la vida algo insoportable. Por tal razón, la muerte de la "víctima" se toma en este trabajo como un problema ético, moral y normativo.

Después de padecer hambre en carne propia, puedo decir que he comprobado metafísicamente lo implícito de la ética de la liberación y he aprendido a callar lo sabido, aquello que la palabra no alcanza a decir, aquel silencio que habla, que interpela sin escribir. Los argumentos contundentes de este trabajo no están escritos explícitamente porque se sitúan más allá de la realidad, ahí donde lo real del no-ser se revela en el Otro, en la vida humana de la "víctima" al borde de la muerte.

Aquel ser humano que el sistema hegemónico vigente ha reducido a mediación para la producción de plusvalor, no tiene valor como muchas éticas formales han buscado, puesto que la vida humana es el fundamento de todo valor. En consecuencia, la vida humana no puede tener una ética de valores. La vida humana tiene "dignidad", y esto es mucho más que el valor, y dicha "dignidad" vive en los sectores más explotados, más robados y más empobrecidos. Debido a esto, la ética de la liberación está vigente y sus argumentos no están escritos en un texto erudito, ni son un discurso hablado en clase dentro de un aula universitaria, sino en la exterioridad, fuera de la totalidad que intenta totalizar lo intotalizable, lo inalienable. El ser humano crítico es el que siempre luchará por la liberación de las víctimas de los sistemas perversos que piden en sacrificio la sangre de inocentes, sistemas racistas y excluyentes en los que, por el hecho de ser distinto, el Otro es asesinado con misiles y violencia que siembra hambre, pobreza, injusticia, decadencia y muerte.

En este trabajo quizá digo menos de lo que quiero decir porque lo formal de la escritura nunca llegará al contenido real de la ética de la liberación. La palabra escrita, otro modo de formalidad, nunca alcanzará el grito vivencial y desgarrador del ¡ay! en agonía. En los límites de la vida se encuentran los límites de la ética de la liberación; en la muerte del Otro, de la "víctima", la ética se acaba y comienza la política como acción estratégica, como praxis de liberación fáctica, concreta y real.

Después de estar en los límites de la ética, después de ver la muerte del Otro, he padecido también la alegría de niños, mujeres y hombres que conviven en hermandad, compartiendo la risa y una taza de café en medio de la pobreza, 
esperando la noche debajo de un techo de láminas de cartón. He visto la esperanza de vivir un día más en medio del frío, en medio de la niebla de los montes donde los rostros se cubrían con pasamontañas para conservar el calor de los vivos, para conservar la vida y luchar con "dignidad" para no morir. He comprendido la lucha a muerte por la sobrevivencia y por la transformación ética para la liberación.

En el presente texto intento probar que las éticas formales dejan fuera el contenido material de la ética, es decir, niegan al sujeto corporal vivo, mostrando así lo insuficiente que es el ámbito de la validez formal sin el principio material y sin su aplicación fáctica. La hipótesis es: la ética de la liberación es capaz de ir desde el contenido material de la ética hasta más allá de los principios de las éticas formales, al profundizar en el análisis de la vida negada de las víctimas humanas de un sistema hegemónico vigente. Con ello se demuestra que la ética y la política no están separadas, sino que los principios de la ética de la liberación se pueden fundamentar en niveles más concretos, en una política de la liberación ética. La ética de la liberación no permanece sólo en niveles abstractos; antes bien, en la política de la liberación quedan subsumidos los principios éticos, para mostrar que la política debe ejercerse bajo principios éticos.

El método de trabajo comienza por el análisis de las éticas de dos autores representativos en la historia de la filosofía: Aristóteles e Immanuel Kant, para posteriormente contrastar sus aportes filosóficos con la ética de la liberación con el objeto de mostrar que el contenido material de la ética — la vida humana misma - es necesario para una ética material. Una vez cimentada la vida humana como principio y contenido material, se pasa al análisis de las concepciones de la vida mediante el estudio de la evolución creadora de la vida en la filosofía de Henri Bergson, que supera el racionalismo, para llegar con semejante análisis a la muerte y ruptura de la vida humana como finitud. Posteriormente, con Hans Jonas nos adentramos en el principio de responsabilidad como preocupación éticamente angustiosa ante la muerte de la vida, no sólo humana, sino cultural y ecológica para, por último, mostrar desde la perspectiva de la ética de la liberación el mal y la necesaria crítica ética que ésta realiza desde las víctimas que sufren las consecuencias de un sistema hegemónico vigente perverso, impuesto violentamente por el egoísmo de una minoría en el mundo, causante de la exclusión, la injusticia, el hambre, la muerte y la precaria sobrevivencia del $85 \%$ de la población mundial que exige un nuevo orden, un mundo alterno. Además, muestro en el último epígrafe el aporte a la filosofía de la ética de la liberación. 
Con este texto pretendo tener un acercamiento y una mejor comprensión de los escritos del profesor Enrique Dussel, en especial de su Ética de la liberación en la edad de la globalización y la exclusión. La complejidad de sus planteamientos filosóficos me ha mostrado la importancia, el compromiso y la seriedad que se requieren para trabajar los problemas filosóficos en los países de la periferia. 


\section{PRINCIPIO MATERIAL DE LA ÉTICA}

Para tener el espíritu despierto, no sólo contamos con el café, la enfermedad, el insomnio o la obsesión de la muerte; la miseria contribuye también en igual o mayor medida: el terror al día siguiente tanto como el de la eternidad, los problemas de dinero tanto como los espantos metafísicos, excluyen el reposo y el abandono. Todas nuestras humillaciones provienen de que no podemos resolvernos a morir de hambre.

E.M. Cioran

\section{La ética formal aristotélica}

El bien como fin

"El bien es aquello hacia donde todas las cosas tienden". ${ }^{1}$ Todas nuestras acciones tienden hacia algún fin que queremos por sí mismo, y lo que realizamos por medio de las acciones es por causa de este fin, que nos impulsa a actuar siempre con tendencia hacia lo bueno y lo mejor. Al conocer y tener claro el fin, se alcanzará de mejor manera lo que se pretenda; es decir, si hay un fin delimitado, un objetivo, será más fácil trazar un camino y llegar a él de una manera estratégica.

En su Ética nicomáquea, Aristóteles intentó determinar esquemáticamente cuál es este fin y a qué facultad pertenece. Como el fin tiende hacia lo bueno y lo mejor, entonces lo más alto es el ser supremo que dirige, de tal modo que éste, el ser supremo, es aquel al que pertenece el fin.

1 Aristóteles, Ética nicomáquea (Madrid: Gredos, 1993), L.I, p. 5ss. 1094 a 10 ss. 
El fin se manifiesta en la política, ya que ésta determina y señala qué ciencias son necesarias en las ciudades, cuáles ha de aprender cada ciudadano y hasta qué extremo. La política decide qué se debe hacer y qué se debe evitar para el bien de cualquier ciudad y de cada ciudadano. Así, la política es el fin, porque el bien de la ciudad es también el del individuo que vive de la ciudad, y es hacia donde tiende lo bueno y lo mejor. El ser humano es, en sí mismo, el bien del individuo y el de la ciudad; él mismo es el fin.

\section{El bien supremo como felicidad}

“El fin de la política no es el conocimiento sino la acción". 2 Para Aristóteles, el bien es orientado por los individuos a través de sus acciones, siendo éstas conducidas por medio de la razón, el saber. Si las acciones no son orientadas por la razón, entonces el conocimiento no será de provecho. Por tanto, la educación del ciudadano consistirá en aprovechar el conocimiento para el bien común y orientar las acciones por medio de la razón. Todo conocimiento y toda acción tienden a algún fin, y el fin de la política es el bien supremo de las mayorías, es la felicidad del individuo en la ciudad con los demás ciudadanos. Nos dice el Estagirita: "Vivir bien y obrar bien es lo mismo que ser feliz". 3

Si se quiere ser feliz en la ciudad, la política debe ser bien conducida por sus costumbres. Éstas se asimilan por medio del aprendizaje, el cual es adquirido a través de la educación que se imparte a los discípulos, que orienta sus acciones por conducto de la razón para aprovechar y hacer buen uso de lo bueno y lo justo, o dicho en otros términos, se debe ejercer bien la política.

El bien es realizable. El bien supremo para Aristóteles es el bien que se busca a sí mismo, es el que nunca se va a elegir por otra cosa; este fin supremo es la felicidad, a la que tienden todas nuestras acciones. Al tratar de alcanzar la felicidad se buscan honores, placer, inteligencia y toda virtud, pero la felicidad no se alcanza por medio de esto. El bien supremo, el ser feliz, no lo alcanza uno mismo solo, sino en relación con los demás, con los ciudadanos en la ciudad, ya que el hombre es por naturaleza un ser social. De esta forma, la felicidad se alcanza en el bien de la ciudad y los ciudadanos.

"Toda acción y decisión es el fin, pues es con vistas al fin como todos hacen las demás cosas". ${ }^{4}$ Aristóteles ve en la felicidad el fin de los actos, ya que todas

\footnotetext{
2 Aristóteles, Ética nicomáquea, L.I, p. 5ss. 1094a 10 ss.

3 Aristóteles, Ética nicomáquea, L.l, p. 15ss. 1095a 20 ss.

4 Aristóteles, Ética nicomáquea, L.l, p. 20ss. 1097a 25ss.
} 
nuestras acciones están dirigidas a lo más deseable de todo, la felicidad, y esto es algo perfecto y suficiente.

\section{La virtud como bien del alma}

"La función del hombre es una cierta vida, y ésta es una actividad del alma y unas acciones razonables, y la del hombre bueno estas mismas cosas bien y hermosamente, y cada uno se realiza bien según su propia virtud". ${ }^{5} \mathrm{El}$ hombre, para Aristóteles, tiene funciones específicas que son el vivir y el sentir, como lo es también para cualquier planta o animal; pero la única función privativa del hombre ,a diferencia de los demás seres vivos, es la actividad propia de un ente que tiene razón. En síntesis, el hombre es una vida sensitiva racional, y la razón es una forma de actividad del alma.

Los bienes del alma son los más importantes para este filósofo, ya que las acciones y las actividades anímicas están referidas al campo del alma. El fin, esto es, la felicidad, se trata de alcanzar por acciones y actividades que son bienes del alma. El hombre feliz vive bien y obra bien, lleva una buena vida y buena conducta. "El bien del hombre es una actividad del alma de acuerdo con la virtud, y si las virtudes son varias, de acuerdo con la mejor y más perfecta, y además en una vida entera". ${ }^{6}$

Así, para Aristóteles, aquellos que actúan rectamente alcanzan las cosas buenas y hermosas porque el hombre es acción y son nuestras acciones las que nos hacen felices o desgraciados. El que juzga rectamente, de acuerdo con la virtud, realiza acciones que son agradables por sí mismas, así como buenas y hermosas. En este sentido, la virtud se identifica con la felicidad: "La actividad conforme a la virtud es una actividad propia de ella". 7

Sin embargo, la virtud para Aristóteles está en el alma, en su naturaleza, en el hombre como actividad, porque la felicidad requiere una virtud perfecta y una vida entera; esto sólo se puede encontrar en el alma. Si la virtud está en la naturaleza del hombre, es en el alma donde reside lo racional y lo irracional como una mezcla homogénea indivisible. Nuestro filósofo elogiará la parte racional del alma y la razón, ya que ésta conduce rectamente a hacer lo mejor para él y para la ciudad. Así, la virtud no está en todos, sólo en el hombre libre, el hombre

\footnotetext{
5 Aristóteles, Ética nicomáquea, L.I, p. 10ss. 1098a 20 ss.

6 Aristóteles, Ética nicomáquea, L.l, p. 10ss. 1098a 20 ss.

7 Aristóteles, Ética nicomáquea, L.I, p. 30ss. 1099a 5ss.
} 
de razón, el hombre griego; este es el único que puede preocuparse de la felicidad. En otras palabras, la virtud es de aquellos que no están incapacitados para alcanzarla, como sí lo están el niño que sólo la detenta en potencia, aquel que no posee linaje, y la mujer y el esclavo, que no son racionales. Por lo demás, la virtud y los bienes exteriores son necesarios para lograr la felicidad y sólo el ciudadano con propiedades puede llegar a ser feliz. "'La felicidad' es una cierta actividad del alma de acuerdo con la virtud". ${ }^{8}$

\section{La ética formal de Aristóteles}

"La sabiduría, la inteligencia y la prudencia son dianoéticas, mientras que la liberalidad y la moderación son éticas". 9 Para Aristóteles, entonces, la ética es lo que procede de la costumbre porque la costumbre puede perfeccionar las virtudes del hombre por medio de la cultura y la comunidad, y siempre se produce a posteriori a través de la educación; por otra parte, la cultura, la comunidad, la familia, la pareja y la madre, son siempre a priori. Por lo tanto, la ética para este filósofo es la formación de diversos modos de ser por medio de la domesticación de la recta razón en lo relativo a nuestras acciones con el término medio, la fronesis, es decir, la moderación y la virilidad, no en el exceso ni en su defecto, sino en su término medio.

Por todo lo dicho anteriormente, la virtud es parte de la razón, y su parte racional es la que se elogia, pues es la que exhorta a que nuestras acciones sean moderadas. El hombre racional, por lo tanto, es el ciudadano, que es el único que puede tener virtudes. La felicidad es el fin del hombre de la ciudad y sólo éste puede acceder a ella por medio de su virtud, de modo que si el hombre es feliz, puede hacer felices a los ciudadanos siempre en la moderación de sus acciones. El justo medio de la justicia en la ciudad es la felicidad si todos sus ciudadanos son felices. Así, la justicia es felicidad y también es ética. "Llamamos justo a lo que proceda o preserva la felicidad o sus elementos para la comunidad política". ${ }^{10}$

La ética adquiere su desarrollo perfecto en la política, en las leyes de la ciudad que legislen el correcto comportamiento en la comunidad, que debe estar justamente organizada por una serie de reglas. La ética de Aristóteles, entonces,

\footnotetext{
8 Aristóteles, Etica nicomáquea, L.I, p. 25ss. 1099a 30ss.

9 Aristóteles, Ética nicomáquea, L.l, p. 35ss. 1102a 40 ss.

${ }^{10}$ Aristóteles, Ética nicomáquea, L.V, p. 15ss. 1129b 20 ss.
} 
requiere de principios legislativos para el correcto control de los apetitos instintivos animales del hombre y es, en este sentido, meramente formal.

\section{La ética formal kantiana}

\section{La filosofía práctica y su objeto}

"Al igual que la lógica es una ciencia de la razón, el objeto de lo práctico debe ser su praxis"." Para Kant, la filosofía práctica es la regla del comportamiento, y ésta tiene por objeto la praxis - a diferencia de la filosofía especulativa, que es teórica y tiene por objeto la teoría-. El fundamento de los conceptos de los objetos es analizado por la teoría, pero los fundamentos de la puesta en práctica del conocimiento de los objetos son dados por la praxis. Tal distinción sólo es posible en el conocimiento, es decir, únicamente en la forma podemos estudiar esta diferencia sin considerar el contenido del objeto, porque para este análisis queda fuera y se halla en una posición diferente, tanto a lo teórico, como a lo práctico, ya que, al hacer abstracción del objeto en su momento teórico, da un siguiente paso o nuevo movimiento hacia el comportamiento que propicia una regla para el buen uso de la libertad. Este uso de la regla representa el objeto de la filosofía práctica, ya sin consideración de los objetos, sino de la acción según la regla de comportamiento.

El buen uso del "libre arbitrio" con independencia de cualquier objeto es tema que debe tratar la filosofía práctica. Esta filosofía propicia reglas con respecto al uso de la libre voluntad. Así, la formulación de una regla para el buen comportamiento supone que ésta es objetiva y enuncia lo que debe suceder. La objetividad de la regla es dada en sí misma, pues en la filosofía práctica se contiene la ciencia de la regla para conducir al hombre como debe. La antropología es la ciencia que da la regla de la conducta efectiva, esto es, se ocupa de las reglas subjetivas de cada hombre y es la que conduce la subjetividad hacia lo que debe suceder en su actuar. Por lo tanto, la antropología sostiene la moral del hombre, que es la que intenta regular la buena conducta. Si la filosofía no contempla al sujeto antropológico como parte primordial, entonces es filosofía especulativa. De esta manera, la filosofía práctica o moral se entiende en relación con su objeto, que es la conducta, y con las reglas que deben regular tal conducta para llevarla hacia la bondad.

"Emmanuel Kant, Lecciones de ética (Barcelona: Crítica, 1998), 40. 


\section{El bien supremo}

"El imperativo moral manda, pues, absolutamente, sin atender a los fines". ${ }^{2}$ Tanto para Kant, como para Aristóteles, la felicidad es el fin universal de los hombres y es por este fin por el que se establece una regla de juicio sobre aquello que sea la felicidad.

Para Kant el fin ya está determinado, es la felicidad. Sin embargo, para alcanzarla se debe delimitar el fin, es decir, saber qué es la felicidad, y una vez aclarado el fin, se debe echar mano del uso de los medios adecuados para acceder a dicha felicidad. Es decir: "Se trata, pues, de una regla del juicio sobre aquello que sea la felicidad y de la regla de uso de los medios adecuados para lograr esa felicidad". ${ }^{13}$

A esto nuestro autor lo llama "imperativo de la sagacidad" y se da en toda persona por instinto, asertórica, universal y necesariamente. Pero, más aún, busca e imagina un imperativo incondicionado o que esté bajo una condición objetivamente necesaria y no subjetiva, como lo es en el caso del imperativo de sagacidad. Este imperativo indeterminado no se dirige por finalidad, es decir, el fin no está determinado por la acción, sino que se produce conforme al libre arbitrio del actuar, sin atender a los fines. Este imperativo es moral, pues manda absolutamente sin atender a los fines. "Nuestro libre hacer u omitir posee una bondad propia, proporcionando al hombre un valor interno absolutamente inmediato, el de la moralidad". ${ }^{14}$

Es en el libre arbitrio donde está contenido el fundamento de la dignidad de la felicidad; éste supone la perfección moral, es decir, que la persona sólo puede aspirar a ser feliz en cuanto se haga digna de dicha felicidad.

Kant va a agregar a la concepción de Aristóteles la dignidad; en otras palabras, la felicidad no es el bien supremo, como lo concebía el griego, sino que además la persona se hace digna de ser feliz. Así, el bien supremo consiste en la conjugación de la felicidad de las personas racionales y la dignidad de la persona justa. De esta manera, el libre arbitrio contiene el fundamento de la dignidad de la felicidad.

\footnotetext{
${ }_{12}$ Kant, Lecciones de ética, 42.

${ }^{13}$ Kant, Lecciones de ética, 41.

${ }^{14}$ Kant, Lecciones de ética, 42.
} 
El principio categórico o de moralidad como mandato

"El motivum morale ha de ser considerado enteramente puro en y por sí mismo". ${ }^{15}$ Kant busca en el principio moral el fundamento para el proceder de nuestra voluntad. La base de su doctrina de la moral está constituida por fundamentos empíricos que se derivan de los sentidos, además de por fundamentos intelectuales que se derivan de las acciones por medio de la razón; por lo tanto, el sistema moral descansa en fundamentos interiores (en un primer momento) y exteriores (en un segundo momento). Es en el sentimiento moral donde se puede distinguir lo que es bueno o malo; este sentimiento es afectado por algo externo —en este caso por la educación o el gobierno- - como lo situaba Aristóteles; es decir, toda moralidad —a diferencia de la moral — es una costumbre, un hábito adquirido por las enseñanzas de una cultura. Dicha costumbre permite o prohíbe cualquier acción y todo juicio depende del ejemplo de la costumbre y la orden de la autoridad, pero esto no es el principio moral, sino sólo el derivado de la experiencia: la moralidad. "Somos civilizados hasta el exceso, en toda clase de maneras y decoros sociales. Pero para que nos podamos considerar como moralizados falta mucho todavía". ${ }^{16}$

El principio moral no puede ser deducido de la experiencia. Es decir, aquellos principios que deben ser válidos universal y necesariamente no son inferidos a posteriori, sino que se infieren de la razón pura, donde toda regla necesaria se establece a priori. Así, el enjuiciamiento de la moralidad no es asunto de los sentidos, sino del entendimiento.

En su obra Fundamentación de la metafísica de las costumbres, Kant menciona que hay una necesidad natural en el hombre y que ésta es el propósito de la felicidad. Tal necesidad se origina a priori en toda persona individual porque pertenece a su esencia.

El imperativo categórico o de moralidad, por no ser hipotético, necesita una explicación en cuanto a la felicidad, pues lo que nos demuestra no depende de la experiencia —ni de ninguna inclinación—, ya que es ilimitado e incondicionado. No obedece a leyes — las cuales forman parte, en su conjunto, de los imperativos hipotéticos- porque es algo más que necesario, y por su condición absoluta es un mandato que apela al libre arbitrio. Los imperativos categóricos o de moralidad están inmersos en la conducta libre en general, esto es, en los actos dados necesariamente en la razón pura de la voluntad divina.

\footnotetext{
${ }^{15}$ Kant, Lecciones de ética, 56.

${ }^{16}$ Emmanuel Kant, Filosofía de la historia (Bogotá: Fondo de Cultura Económica, 1998), 56.
} 
Mostrar el imperativo de moralidad es imposible por su complejidad ante el lenguaje. El imperativo de moralidad sólo nos enseña por medio de la ley que tal imperativo es un precepto pragmático para dar cuenta de su incondicionalidad. De esta manera, tenemos que verlo enteramente a priori porque sólo se devela como ley práctica. Es difícil penetrar en su fundamento y conocerlo en realidad ya que es una proposición sintético-práctica a priori, complicada de mostrar fuera de sí empíricamente; nada más se puede revelar y encontrar en el campo de la metafísica. Lo único que nos indica el imperativo es la máxima de acción ya que ésta aparece como ley incondicionada e ilimitada; por tanto, sólo nos queda la universalidad de la ley.

Una ley universal es una ley de la naturaleza; de esta manera sitúa Kant el imperativo categórico: "Obra como si la máxima de tu acción debiera convertirse, por tu voluntad, en ley universal de la naturaleza". ${ }^{17}$ Eso significa que debe valer para todos. Esta ley universal será el canon del juicio moral de la máxima. Así, todos los deberes quedan en el plano de su propia ley, en su dependencia del principio único. Este principio es parte de la razón pura; en otras palabras, en el imperativo categórico radica el concepto de deber, pero en un plano anterior de la conceptualización, en la metafísica, a priori.

Este imperativo es una forma de la exigencia moral, es una obligación práctica, una ejecución necesaria de nuestras acciones libres. "El sometimiento de nuestra voluntad bajo reglas de fines universalmente válidos supone la bondad intrínseca y la perfección del libre arbitrio, pues así concuerda con todos los fines". ${ }^{18}$ De esta manera, la voluntad moral es el gobierno de nuestro actuar mediante reglas morales con las cuales las acciones de nuestra voluntad cobren validez universal en el libre albedrío.

\section{La buena voluntad como bien supremo}

"Ni en el mundo ni, en general, fuera de él, es posible pensar nada que pueda ser considerado bueno sin restricción excepto una buena voluntad".19 Kant ve un rasgo característico que es único en todas las personas: la voluntad. La voluntad es para este filósofo aquello que rige nuestra vida de una forma pura

\footnotetext{
${ }^{17}$ Emmanuel Kant, Fundamentación de la metafísica de las costumbres (Madrid: EspasaCalpe, 1990), 92.

${ }^{18}$ Kant, Fundamentación de la metafísica..., 55.

${ }^{19}$ Kant, Fundamentación de la metafísica..., 53.
} 
y buena, ya que los talentos del espíritu — como el entendimiento y el juiciolos consideramos cualidades del temperamento y son por lo regular buenos y deseables, aunque también pueden llegar a caer viciados por la maldad —de no ser porque existe una voluntad buena-. En suma, no basta sólo con los talentos del espíritu, sino que hay algo más que hace los actos buenos sin restricción.

La voluntad rectifica y acomoda mediante una ley universal el influjo de la felicidad, el principio de toda acción que es inherente en el ser humano sin que necesite de otro para que califique la acción como buena o mala, porque el ser que ostenta una voluntad pura hace de la voluntad la indispensable condición que nos hace dignos de ser felices.

La buena voluntad no es una simple cualidad que favorezca a la voluntad en sí misma, porque esta última tiene un valor interno absoluto; es decir, es buena. Su valor no reside en lo que se realice o efectúe, sino que es valiosa más allá de los actos y es anterior a ellos; es pura no por algún provecho o inclinación ya que, si se quitara todo tipo de inclinación y de utilidad, sólo nos quedaríamos con el valor de la buena voluntad.

La voluntad no es la razón. Se encuentra en el ser humano y no tiene como destino admirar la naturaleza del uso práctico del instinto, sino que está asignada para otros propósitos más dignos. De esta manera, la razón no puede dirigir la voluntad; sin embargo, estamos dotados de razón —y no simple y llanamente de instintos-, con lo cual la razón tiene necesariamente una facultad práctica. Así: "Esta voluntad no ha de ser todo el bien ni el único bien, pero ha de ser el bien supremo y la condición de cualquier otro, incluso del derecho de felicidad". ${ }^{\circ}$

Por lo tanto, la voluntad no es una inclinación. La voluntad buena se da por el empuje hacia algo sin necesidad de obtener un fin, o dicho de otro modo, actúa "por deber" y no conforme "al deber".

La voluntad libre como ley en sí misma

"Todo ser que no puede obrar de otra manera que bajo la idea de libertad es, por eso mismo, verdaderamente libre en sentido práctico". ${ }^{21}$ La determinación de un juicio no es producto de un impulso, sino obra de la razón, pero en tanto razón práctica; en síntesis, la razón es autora de sus propios principios independientemente de

\footnotetext{
${ }^{20}$ Kant, Fundamentación de la metafísica..., 57.

${ }^{21}$ Kant, Fundamentación de la metafísica..., 131.
} 
todo influjo. Por ello, todo principio debe considerarse libre, porque la voluntad actúa bajo la idea de libertad y se aplica a todos los seres racionales como ley universal por medio de su libertad al ser absolutamente buena.

La máxima que rige en principio la libertad como voluntad es absolutamente buena, siempre y cuando pueda sostenerse a sí misma eternamente, esto es, que sea considerada como ley universal. "Una acción no ha de tener lugar porque Dios la quiera, sino porque es justa o buena en sí misma, y sólo porque dicha acción es así, Dios la quiere y nos la demanda". ${ }^{22}$

La voluntad libre es propiamente una ley porque obra sólo con la máxima de que puede ser objeto de sí misma como ley universal. De esta manera, las leyes morales deben ser universalmente válidas y relativas a las acciones libres en general, sin considerar la divergencia del sujeto, puesto que la voluntad divina es la buena voluntad universal.

La ética formal de Immanuel Kant

"La libertad aumenta con el grado de moralidad". ${ }^{23}$ El libre arbitrio, para Kant, no se dirige por causas impulsivas, como los animales que son constreñidos por estímulos, sino que la acción práctica del ser humano es libre en su ser libre, Dios. Así, bajo la obediencia de la ley moral, y por ende del arbitrio divino, el individuo puede ser recompensado por Dios pues su conducta es adecuada a la ley moral.

Las acciones por estímulos son una construcción subjetiva, mientras que las acciones per motiva son una construcción práctica objetiva con la cual el ser humano se siente constreñido moralmente por motivos inductores de la razón; estos motivos están carentes de estímulos y, por lo tanto, implican mayor libertad. Por esta causa, el ser humano tiene mayor grado de libertad pues con ésta se hace más grande el libre arbitrio y, por lo tanto, es más constreñido moralmente. Semejante constricción es una obligación interna.

La obligación interna se constriñe a sí misma; cuanto más libre sea su construcción, más libre será internamente, y su voluntad será enteramente buena y hará de buen grado todo el bien. De esta suerte, el deber es con uno mismo y se trata de una obligación interna, mientras que la coacción es una obligación externa que se ve afectada por otro más allá de la interioridad individual; es

\footnotetext{
${ }^{22}$ Kant, Fundamentación de la metafísica..., 61.

${ }^{23}$ Kant, Fundamentación de la metafísica... , 68.
} 
exterioridad. Para Kant las obligaciones internas son éticas, mientras que las obligaciones externas son jurídicas. "La ética tiene en cuenta toda obligación cuya motivación sea interna, y la pondera por el deber y por la índole interna de la cosa misma, y no por la coacción". 24

La acción es un deber y se realiza "por deber" al ser ética en sí misma, puesto que es guiada por un buen sentimiento; no se realiza por coacción, sino que es un mandato divino. "Las leyes divinas son al mismo tiempo mandatos divinos o, lo que es igual, el jus naturale es a la vez el jus positivum de la voluntad divina, pero no porque se halle en su voluntad, sino más bien porque se encuentra en la naturaleza del hombre". ${ }^{25}$

Es en la ley divina donde ética y derecho coinciden; es decir, es un mandato de Dios que las acciones éticas y jurídicas sean ejercidas por deber y no por coacción para la buena disposición de ánimo.

En esta ley el sentido es la intención, ya que se necesitan leyes que manden sobre nuestras intenciones; sin embargo, no existe ser alguno que sea autor de las leyes morales; no hay creador porque son prácticamente únicas y necesarias. El espíritu de las leyes morales radica en los sentimientos, pero no como función apetitiva, sino intelectiva: "Aquella sensibilidad que coincide con la fuerza impulsiva del entendimiento sería el sentimiento moral; sin duda, no podemos sentir la bondad de la acción, pero el entendimiento se opone a una acción mala por ser contraria a la regla". ${ }^{26}$

Así, el libre arbitrio es la libertad de elección sin tutela de otro, de algo exterior. En otros términos, el sentimiento intelectivo es el que dirige $-\mathrm{y}$ no agentes externos como el Estado-; es el sentimiento del ser humano el que lo hace libre en su voluntad sin que nadie lo determine para su elección porque se rige por sí mismo. En esta autonomía desligada del otro exterior, Kant considera que surge el camino hacia una vida ilustrada, esto es, comenzar a pensar sin que piensen por nosotros, aunque más parece una vida ideal ya que siempre se requiere del Otro para aprender — como del maestro, por ejemplo—o para amar — del ser amado—.

La facultad para ejercer el uso privado de la razón es la que nos permite cuestionar las leyes exteriores impuestas, pero sólo internamente. Por lo tanto, nadie puede imponer arbitrariamente sobre los sujetos una ley que los prive en su totalidad de toda libertad; esto reprimiría nuestra libre razón y no se podrían

\footnotetext{
${ }^{24}$ Kant, Fundamentación de la metafísica..., 72.

${ }^{25}$ Kant, Fundamentación de la metafísica..., 73.

${ }^{26}$ Kant, Fundamentación de la metafísica..., 84.
} 
acusar los abusos criminales de ciertas doctrinas que nos oprimen y nos dejan sin libertad, como es el caso de la policía mundial y su doctrina terrorista.

Imponer a otras personas por unanimidad una doctrina es caer en la privación y detenimiento del progreso "ilustrado" de la especie humana. Por esto Kant ve en la educación la fuente principal para un progreso hacia el bien. Sin embargo, la educación implantada por el Estado no tiene la finalidad y la importancia que debería tener, es decir, la educación impuesta sólo compete a sus fines de dominio y de expansión territorial, no al dominio para una nueva sociedad libre.

La educación moral, en el idealismo de Kant, debe ser impartida por el Estado y para el Estado moral o burgués; entonces, la reforma del Estado tiene que dar la pauta para una educación cívica en la cual haya una conciencia moral. Lo anterior no depende sólo del Estado, sino también, y en gran medida, de los ciudadanos en la toma de conciencia de esa instrucción. Para Kant la educación debe superar todo e infundir una aversión inmediata frente a las acciones malas. En este sentido, la ética para Kant indica lo que es moralmente bueno, el camino hacia el supremo bien. El derecho no puede proporcionar la cuestión moral, ya que el Estado sólo se encarga de controlar asuntos exteriores, apariencias, dejando la política fuera de análisis. No así en la ética, que proporciona leyes internas morales a priori: "El principio supremo de todo enjuiciamiento moral descansa en el entendimiento y el principio supremo del acicate para ejecutar esa acción descansa en el corazón". ${ }^{27}$

La moral es contraria a toda inclinación, por lo que el satisfacer todas las inclinaciones es patológico. El amor en general y el amor erótico-carnal con el Otro amado son también, para Kant, patológicos. Una ley moral dice lo que debe suceder, guste o no; por lo tanto, no es un satisfactor de nuestras inclinaciones impulsivas animales, sino que está contenida en una especie de alma, sin materia, sin cuerpo, descarnada, sólo en una idea pura, formal. "Cada cual puede hacer con su cuerpo lo que guste, pues es algo que a nadie le importa, pero internamente no se es libre, sino que cada cual está ligado por fines esenciales y necesarios de la humanidad". ${ }^{28}$

\footnotetext{
${ }^{27}$ Kant, Fundamentación de la metafísica..., 72.

${ }^{28}$ Kant, Fundamentación de la metafísica... , 69.
} 


\section{La propuesta ética material de Enrique Dussel}

\section{Fundamento de la ética}

"Se trata de efectuar un largo camino, pero desde su correcto 'inicio' (el Anfag de Hegel o Marx), en este caso por sus contenidos". ${ }^{29}$ Dussel entiende el fundamento ${ }^{30}$ no en su sentido ontológico, ${ }^{31}$ sino de una manera más radical, como lo "anterior" a lo ontológico; más aún, anterior al momento metafísico o ético de Lévinas. ${ }^{32}$ Para

${ }^{29}$ Enrique Dussel, Ética de la liberación en la edad de la globalización y la exclusión (México: Trotta, 1998), 92.

${ }^{30}$ Dussel desarrolló una analítica ontológica, es decir, dilucidó el fundamento de la ética para posteriormente deconstruirlo desde una filosofía crítica. El fundamento mismo es la esencia de la voluntad, porque el poder de la "voluntad de poder" nietzcheana no enuncia una consecuencia, sino la esencia. La esencia de la voluntad es la vida. Más allá de la "voluntad de poder" se da primacía a la "voluntad de vivir". Sólo el viviente puede querer y se tiene que querer para sobrevivir, porque el querer une y liga la vida presente con la vida futura, con la sobrevivencia como permanencia de la vida. La voluntad es "voluntad de vivir" y arranca desde el hacer posible vivir del Otro, del que no puede vivir porque es una "voluntad impotente" por ser la víctima. La vida del ser humano es la realidad misma de la que se parte como corporalidad concreta, siendo la corporalidad humana el lugar de la voluntad. La vida para Dussel es el ser del ser humano en su corporalidad; este viviente humano pone las mediaciones para su misma realización como posibilidades para la vida y tienen "valor". Los entes-valiosos son "condiciones" de la realización de la propia vida, de la voluntad y del poder. La vida humana es la fuente del valor, pero en sí misma no tiene valor porque es el fundamento de todos los valores, tiene “dignidad”. La vida humana es pensada en última instancia como la vida de toda la humanidad; es el fundamento de todo valor.

${ }^{31}$ Heidegger, en su filosofía ontológica, considera que la forma en que se presenta el ser al ente es en el reconocimiento del hombre como mortal en el mundo, el hombre finito jamás intotalizable que mediante un estado de ánimo, que es la angustia frente a la muerte, se sitúa respecto al ente como poder-ser. Es decir, es en el hombre donde hay una apertura, donde se proyecta el mundo. Por medio de esta proyección podemos dar cuenta del ser humano como existente dentro del mundo, como "ser en el mundo". El ser humano es el sujeto en el cual, como ente, se funde todo ente; se convierte en el centro de la referencia del ente como tal. El ser humano constituido como "ser ahí" es aquel que se abre al ser y pone a la luz el "ahí".

32 Para Lévinas, la exterioridad es un situarse fuera del orden gnoseológico. El desear metafísico de Lévinas atraviesa el horizonte de psiquismo del mundo, del sistema o totalidad de Heidegger, rompiendo con ello porque penetra hasta la intimidad del Otro; es creadoa en cuanto al movimiento de salir. El poner en cuestión al otro y no verlo ya 
nuestro filósofo, el fundamento es lo anterior a la ontología y a la ética de Lévinas, es lo pre-ético: la vida humana. La vida humana es el fundamento en el que se funda todo valor, es por esto que la ética dusseliana no es una ética de valores.

\footnotetext{
Todo acto cognitivo (ego cogito), todo "lugar" del enunciado, todo sistema, el "mundo" de todo Dasein, toda intersubjetividad consensual discursiva, todo pre, sub o inconsciente, toda subjetividad anterior al "mundo" presupone siempre ya a priori un sujeto humano concreto vivo como último criterio de subjetividad — de referencia a un actor en última instancia como modo de realidad-.33
}

\section{El momento material de la ética}

"Esta es una ética de la vida, es decir, la vida humana es el contenido de la ética". 34 La ética de Dussel es de contenido material y este contenido es la vida humana; es una ética de la vida, una antropología post-metafísica y post-ontológica, es trans-meta-física ética.

La vida de la que se habla es la vida humana, antropológica, que comprende tres niveles: 1) físico-biológico, que es la estructura afectiva neuro-cerebral; 2) ético-estético, que es lo histórico-cultural; pero más aún: 3) místico-espiritual, que son las creencias siempre en un ámbito comunitario.

Lo material es aquí lo opuesto a lo formal, es lo contenido. La vida humana como el contenido de la ética es un "modo de realidad", es decir, la vida humana no es un concepto, una idea, un horizonte abstracto o concreto, no es un "modo de ser", sino un "modo de realidad", porque es desde la vida humana desde donde se encara la realidad, que se constituye a partir de un horizonte ontológico. Es el punto de partida, es lo pre-ontológico de lo ontológico, donde lo real se actualiza como verdad práctica.

como lo mismo es "ética", pero una ética que cumple la esencia crítica del saber. El diálogo, la puesta en cuestión de lo mismo por el Otro, es la crítica a la totalidad desde la exterioridad, desde el Otro más allá de mi yo. Esta exterioridad es la ruptura de la totalidad; este "poner en cuestión" es la esencia de la crítica, el diálogo. Esto es la ética para Lévinas. Por su parte, Dussel va hacia algo más radical pero subsumiendo este pensar e interpretándolo para redefinir la ética. Lévinas supone la vida humana, pero Dussel la impone como contenido material, como lo pre-ético, anterior al momento metafísico o ético de Lévinas, superándolo, siendo éste metafísico.

33 Dussel, Ética de la liberación..., 521.

34 Dussel, Ética de la liberación..., 91. 
El momento material de la ética se explica por sus contenidos. En este caso, el contenido es la conservación de la vida humana. Las pulsiones tenderán hacia este fin, que es la conservación de la vida y hacia donde tiende todo nuestro accionar. Dicho fin no es la felicidad, como lo concebían las éticas de Aristóteles y Kant.

El comportamiento pulsional-corporal del ser humano para conservar la vida, para no morir, cumple con las exigencias de las anteriores éticas; es, en resumen, universal y necesario. Esta condición alcanza otros niveles que sobrepasan el egoísmo puro de Kant, como es el caso de la sobrevivencia de una especie en peligro de extinción — como la humana-. De esta manera, todo fin tenderá a la conservación de la especie con consensualidad válida formal y sus aplicaciones prácticas factibles para conseguir lo bueno. Entonces, el contenido material tiene una universalidad que rompe con el principio categórico egoísta de Kant.

Por otro lado, Kant entiende la facultad apetitiva como fundamento determinante de la voluntad. Los principios prácticos que presuponen un objeto son empíricos y, por lo tanto, estos principios que se basan en la facultad apetitiva no pueden conducir a leyes prácticas. Dussel señala: "Las leyes prácticas son universales, y parece que la facultad apetitiva es egoísta”.35

Para Kant, conservar la vida es un deber y todos tenemos una inclinación inmediata a hacerlo de ese modo, de manera que el cuidado angustioso de la conservación de la vida no tiene un contenido moral.

Sin embargo, esta facultad apetitiva tiene una pretensión de universalidad para Dussel; más aún, la inclinación, la pulsión o el deseo son comportamientos para la conservación de la vida. Entonces, conservar la vida depende del criterio y del principio material de la ética; a saber: la vida misma. El ser viviente es el contenido por el cual la vida se conserva y tal inclinación de conservación cumple con la exigencia de universalidad y necesidad. Este cumplimiento pulsional de conservación es en parte una estructura no-intencional.

Con esto queda descartada la hipotética alma de Descartes o Kant, porque el alma es des-dualizada y se encarna debajo de la piel. El alma es el cuerpo, la carne, el contenido material; es el lugar donde metafísicamente se comprende la corporalidad sufriente de lo exterior más allá de mí; es decir, el Otro que sufre las consecuencias no-intencionales de la injusticia y no es captado como ente o como ángel sin cuerpo en la conciencia pura que cerraba la posibilidad de cualquier

${ }_{35}$ Dussel, Ética de la liberación..., 92. 
análisis posterior, sino en su corporalidad sufriente. "El Otro, carnalidad sensible (como el yo psíquico), aparece al contacto no sólo como rostro, sino como víctima". ${ }^{36}$

La intención de una ética-crítica

“[...] el criterio de criticidad o crítico (teórico, práctico, pulsional, etc.) de toda norma, acto, microestructura, institución o sistema de eticidad parte de la existencia real de 'víctimas', sean por ahora las que fueren. Es 'criticable' lo que no permite vivir". ${ }^{37}$ La vida no es razón; la vida humana es fuente de toda racionalidad y la última referencia de la razón es la verdad. Así, la vida humana es la condición que ofrece la posibilidad para la realización de la verdad. De esta manera, el ejercicio intersubjetivo y veritativo de la racionalidad, de lo humano, es un constitutivo intrínseco de la exigencia de la vida. Entonces, la razón es una astucia de la vida y la racionalidad de lo humano es una exigencia de la vida. La razón, entonces, se define ante las pulsiones de muerte del Otro, del excluido, del asesinado. "La alteridad de las víctimas descubre como ilegítimo y perverso el sistema material de los valores, la cultura responsable del dolor injustamente sufrido por los oprimidos, el 'contenido', el 'bien”". ${ }^{38}$

La vida siempre funda la posibilidad de negar la vida y esta negación de la vida (la muerte) es inevitable, ya que pone en evidencia al cínico que trata de justificar la muerte, el suicidio, dándonos la posibilidad de develar la injusticia de cualquier sistema de dominación o perversión que niega la vida de las víctimas. "Nuestra intención última es justificar la lucha de las víctimas, de los oprimidos, y no el pretender argumentar racionalmente para fundamentar la razón a causa de ella misma". 39

El principio material de la ética

"Toda norma, acción, microestructura, institución o eticidad cultural tienen siempre y necesariamente como contenido último algún momento de la producción, reproducción y desarrollo de la vida humana en concreto". ${ }^{40}$ La vida

\footnotetext{
${ }^{36}$ Dussel, Ética de la liberación..., 366.

37 Dussel, Ética de la liberación..., 369.

${ }^{8}$ Dussel, Ética de la liberación..., 311-312.

39 Dussel, Ética de la liberación..., 92.

$4^{40}$ Dussel, Ética de la liberación..., 91.
} 
humana como criterio material universal de la ética se expone en tres momentos: 1) producción, 2) reproducción, y 3 ) desarrollo de la vida humana.

El ser humano no es un ángel ni una piedra, ni siquiera un primate superior. Es un ser viviente lingüístico, autoconsciente y por ello autorreferente, porque recibe la vida "a cargo de" o bajo su responsabilidad. Es un "yo corpóreo" como subjetividad, es la piel desde adentro. En este contenido de la ética no se tiene un cuerpo, sino que se es un cuerpo, se es corporal, porque la subjetividad humana es un momento de su propia corporalidad. El ser humano es un viviente que se vuelve responsable de la vida que tiene a cargo. Cuando Dussel se refiere al principio material de la ética, se refiere a la "autorreproducción de la vida humana". Así, la vida humana es este criterio de verdad práctica.

La ética de la liberación del filósofo Dussel parte de la crítica ética desde la negación de la vida, de los que no pueden vivir, de las víctimas de cualquier sistema; es esto lo que se quiere des-encubrir. La vida como contenido de la ética no es un "vitalismo", sino una lucha por no morir de los movimientos de transformación, ya sean promovidos por indios, africanos, caribeños, chicanos, grupos populares, mujeres, etcétera, que luchan por la vida del "sujeto ético humano corporal". Es en función de las víctimas, de los dominados y de los excluidos, como se describe el principio ético material con pretensión de verdad práctica :

\footnotetext{
El que actúa éticamente debe (como obligación) producir, reproducir y desarrollar autorresponsablemente la vida concreta de cada sujeto humano, en una comunidad de vida, desde una "vida buena" cultural e histórica (su modo de concebir la felicidad, con una cierta referencia a los valores y una manera fundamental de comprender el ser como deber-ser, por ello con pretensión de rectitud también), que se comparte pulsional y solidariamente teniendo como referencia última a toda la humanidad. ${ }^{41}$
}

Este principio material de la ética, en su pretensión de universalidad y de verdad práctica, se va desarrollando en todas las culturas y las motiva por dentro; es la manera de vivir la "vida buena", feliz. Sin embargo, la pretensión de verdad no es la pretensión de bondad porque la bondad es algo más que verdad y validez.

${ }^{41}$ Dussel, Ética de la liberación..., 140. 
La bondad en la ética de la liberación

"No debe extrañar, entonces, que esta Ética sea una ética de afirmación rotunda de la vida humana ante el asesinato y el suicidio colectivo a los que la humanidad se encamina de no cambiar el rumbo de su accionar irracional". ${ }^{42}$ Válida es la acción que se acepta como racional y simétricamente decidida, pero la acción no puede ser buena si antes no se valida. De esta suerte, el principio discursivo de validez quedaría formado, según Dussel, de la siguiente manera: "El que obra moralmente debe llegar a la decisión válida gracias a la participación simétrica de una comunidad de comunicación de los afectados por medio de la argumentación racional —y no por coacción de ningún tipo".43

Pero la simetría no se alcanza en una comunidad real de comunicación empírica, pues siempre hay un grado de imperfección no-intencional.

La moral formal de la validez intersubjetiva es insuficiente al no poder integrar el momento material de la moral práctica. La posibilidad de validez de una máxima universal consiste en la aceptabilidad de los demás miembros de la comunidad, incluyendo la comunidad de los "afectados". Como ya hemos visto, Dussel describe el principio ético material de la siguiente manera: "Todo el que obre éticamente debe producir, reproducir y desarrollar la vida humana en comunidad, en último término de toda la humanidad, es decir, con pretensión de verdad práctica universal". ${ }^{4}$

La vida humana es el "modo de realidad" desde donde se jerarquizan los valores y los fines; es decir, la vida humana no es condición de posibilidad para una argumentación, sino que es un "modo de realidad". Por otro lado, como ya se dijo anteriormente, la bondad es algo más que la verdad y validez. El principio de factibilidad estaría aunado a estas dos pretensiones y Dussel lo enuncia así: “El que obra éticamente debe ejecutar una acción que sea 'posible', empírica, técnica, económica, política, históricamente, dentro de los marcos definidos por los dos principios anteriores". 45

Todo acto tiene un grado de imperfección que produce error, maldad o injusticia, e intentar un acto imposible no puede ser bueno puesto que la perfección es imposible. Por lo tanto, el bien se torna insostenible desde la víctima

\footnotetext{
${ }^{42}$ Dussel, Ética de la liberación..., 11.

${ }^{43}$ Enrique Dussel, Hacia una filosofía política crítica (Bilbao: Desclée Brouwer, 2001), 67.

44 Dussel, Hacia una filosofía política crítica, 74.

45 Dussel, Hacia una filosofía política crítica, 76.
} 
no-intencional; es decir, el bien se torna mal. La crítica de dicho sufrimiento nace desde los que no pueden vivir, y el principio se enuncia de la siguiente manera: "Debe ser criticado todo sistema institucional (o acto, etc.) que no permite vivir a sus víctimas, potenciales miembros negados, excluidos del sistema que tiene la pretensión de reproducir la vida". ${ }^{46}$

Las víctimas, al tomar conciencia, constituyen una comunidad crítica en la que forman juicios negativos del sistema y una utopía posible. El principio de validez crítico, entonces, se enunciaría así: “Al organizar las víctimas simétricamente una comunidad de vida y comunicación deben criticar al sistema que las niega (negatividad) y proyectar una alternativa futura que lo transforme y sustituya (positividad)". 47

Finalmente, dentro del principio de factibilidad, pero ahora crítico, el último principio quedaría del siguiente modo, buscando siempre las transformaciones posibles: "La comunidad crítica debe de-construir efectivamente el sistema, su negatividad y transformarlo (o producir otro nuevo) para que las víctimas puedan vivir, participando simétricamente en las decisiones". ${ }^{48}$

Estos seis principios son necesarios, mas no suficientes. Con esto se pretende hacer una ética más completa, crítica, democrática y fáctica, con pretensión de universalidad, que trata de llegar a la bondad; dicho en otros términos, con pretensión de bondad.

No pretende la Ética de la liberación ser una filosofía crítica para minorías, ni para épocas excepcionales de conflicto o revolución. Se trata de una ética cotidiana, desde y a favor de las inmensas mayorías de la humanidad excluidas de la globalización, en la "normalidad" histórica vigente presente.49

\footnotetext{
${ }^{46}$ Dussel, Hacia una filosofía política crítica, 82.

47 Dussel, Hacia una filosofía política crítica, 83.

${ }^{48}$ Dussel, Hacia una filosofía política crítica, 84.

49 Dussel, Ética de la liberación..., 15.
} 


\section{LA CONCEPCIÓN DE LA VIDA}

El tiempo se encarga de colocar luego los hechos en
su debido rango, y cosas que en su inicio parecen
triviales se revelan después en toda su trascendencia.
Y así, el pasado no es algo cristalizado, como algunos
suponen, sino una configuración que va cambiando a
medida que avanza nuestra existencia y que alcanza
su sentido verdadero en el instante en que morimos,
cuando ya para siempre quedará petrificado.

Ernesto Sabato

\section{La evolución creadora de la vida en la filosofía de Henri Bergson}

Cuerpo vivo

"Aun en el caso de encontrarse solo y no hacerse otra cosa que pensar, en realidad, aun entonces, el hombre se habla a sí mismo". ${ }^{50}$ Bergson, en su libro La evolución creadora, nos hace ver que la ciencia, desde su punto de vista objetivo, aísla sistemas y encierra sociedades; sin embargo, la materia no llega a ese extremo y el aislamiento nunca es total. Es decir, para nuestro pensador, en un sentido epistémico, los cuerpos brutos son recortados del tejido de la naturaleza por una percepción; al recortar del todo una parte, la percepción es la tijera con que se corta. El recorte es hecho en el tiempo en que transcurre la acción, siendo lo "aislado" absorbido en el todo, en el universo. Lo aislado de la parte es sólo un punto en el espacio vacío de la ciencia.

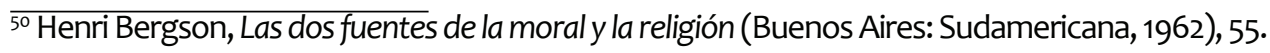


El "cuerpovivo" queabstraees el que recortay pone sus organismos sensoriales para realizar la acción de análisis. Esto, a lo que Bergson llama "cuerpo vivo", ha sido aislado y cerrado por la naturaleza misma; es un individuo realizándose porque las propiedades de la vida siempre están en vías de realización y tienden a reproducirse para no estar aisladas en su totalidad ya que siempre encuentran un antagonista. En caso de que no lo encontraran, la reproducción de la vida sería imposible. "La reproducción de los organismos unicelulares consiste en eso mismo: el ser viviente se divide en dos mitades, cada una de las cuales es un individuo completo". ${ }^{51}$

El tiempo y la evolución

"Donde quiera que algo vive, hay en algún sitio un registro abierto en el que se inscribe el tiempo". ${ }^{52}$ La constante transformación del embrión va acompañada de destrucción organizada, de manera que la crisis de un sistema es la preparación gradual para llegar a un nuevo estado de evolución, y es en el tiempo donde el ser vivo experimenta el corto intervalo que le es dado para vivir. Este proceso de consumación de tiempo es inevitable e irreversible ya que el organismo brota en un esfuerzo para la reproducción.

"Continuidad de cambio, conservación del pasado en el presente y duración verdadera son atributos que el ser vivo parece compartir con la conciencia". 53 Para Bergson, la conciencia de la duración de la vida es lo más indiscutible de la experiencia, y es ésta la causa por la que no se puede rechazar totalmente la experiencia de un sistema.

El tiempo para nuestro autor no incluye pasado ni futuro, sino que se trata de un presente que transcurre, de un modo que es incalculable para las matemáticas. Si el tiempo del que habla Bergson fuera medible, sería absurdo, sin sentido, y la realidad de lo humano sería trágica pues habría un fin ya determinado, un destino dado.

"Si hay finalidad en el mundo de la vida, abarca la vida entera en un único e indiscutible abrazo". ${ }^{54}$ Resumiendo, el finalismo como muerte abraza la vida para poder reproducirse; la muerte, entonces, es una condición necesaria para la reproducción de la vida entera.

\footnotetext{
${ }^{51}$ Henri Bergson, La evolución creadora (Madrid: Espasa-Calpe, 1973), 26.

${ }^{2}$ Bergson, La evolución creadora, 28.

53 Bergson, La evolución creadora, 33.

${ }^{54}$ Bergson, La evolución creadora, 50.
} 
"La vida se manifiesta como una corriente que va de un germen a otro germen por mediación de un organismo desarrollado". ${ }^{55}$ La vida en el abrazo con la muerte no sabe qué gana ni qué pierde en el proceso de evolución; así, el tiempo real que se vive en el "cuerpo vivo" no se piensa ni se mide, porque el tiempo real desborda la inteligencia.

"El acto libre es inconmensurable con la idea, y su 'racionalidad' debe definirse por esa misma inconmensurabilidad que permite hallar en él toda inteligibilidad como se quiera. Ése es el carácter de nuestra evolución interior. Y ése es también, sin duda, el de la evolución de la vida". ${ }^{56}$ El tiempo transcurre en el interior de nuestra evolución; es en el "cuerpo vivo" donde se muere constantemente para seguir reproduciéndose la vida. Con esto, Bergson critica severamente las filosofías finalistas y mecanicistas, unas porque totalizan o idealizan la parte, y otras porque llevan a la inutilidad y a la absurdez de la inteligencia. "El error del finalismo radical, como el del mecanicismo radical, consiste en llevar demasiado lejos la aplicación de ciertos conceptos naturales de nuestra inteligencia. Originariamente sólo pensamos para actuar”. ${ }^{57}$

El impulso de la evolución

"La vida, desde sus orígenes, es la continuación de un único impulso que se ha dividido en líneas de evolución, divergentes"..$^{8}$ Para nuestro filósofo, la razón sólo es la parte que interpreta racionalmente, mientras que el impulso original es un impulso común. El impulso hace que las partes se adhieran al movimiento continuo, adaptándose.

"Cada individuo, sólo retiene del empuje global de la vida cierto impulso, y pretende utilizar esa energía en su interés propio; en esto consiste la adaptación". 59 La variación que produce una especie nueva brota del esfuerzo del ser vivo para adaptarse a las condiciones en que ha de vivir. Así, la conciencia y la voluntad son para Bergson principios internos y psicológicos de desarrollo, y la adaptación, por lo tanto, es parte de la evolución.

\footnotetext{
55 Bergson, La evolución creadora, 36.

${ }^{56}$ Bergson, La evolución creadora, 54.

57 Bergson, La evolución creadora, 50.

${ }^{58}$ Bergson, La evolución creadora, 58.

59 Bergson, La evolución creadora, 56.
} 
La selección natural ha sido una justificación utilizada para fines de explotación y de dominación; por lo tanto, la adaptación sugerida por la evolución ha excluido a ciertos organismos, lo que ha dado como resultado una transformación hacia una sociedad cerrada.

Bergson concibe que de un tronco común se han desprendido sociedades que, al ir haciéndose especie, han llegado a formar sociedades nuevas. Este desprendimiento, para una cultura no-occidental, no es más que vil exclusión e intolerancia hacia lo diferente. "Los hábitos contraídos por un individuo no tienen, probablemente, ninguna repercusión en sus descendencias; cuando la tienen, la modificación que aparece en los descendientes puede no tener ningún parecido visible con la modificación original”. ${ }^{60}$

\section{El hábito, la prohibición y la obediencia}

"Una cosa es un organismo sometido a leyes necesarias y otra una sociedad constituida por voluntades libres". ${ }^{61}$ Para Bergson, la prohibición es un obstáculo para nuestra libertad de obrar. Los hábitos de la vida cotidiana, las costumbres, se obedecen en su mayoría y ejercen una fuerza sobre nuestra voluntad, y es por esta presión por la que como humanos nos sentimos obligados. La presión de la obligación social o cultural se ejerce con tal fuerza sobre nuestra voluntad, que nos obliga a obedecer por obligación al hábito. Nuestro autor ubica la obediencia al hábito en una más elevada forma, en una diferencia de grado de la naturaleza, ya que las obligaciones que impone el hábito le permiten sobrevivir a la sociedad humana en su conjunto de seres libres, dándole una regularidad que simplemente tiene analogía con el orden inflexible de los fenómenos de la vida.

"La ley física tiende a revestir, para nuestra imaginación, la forma de un mandato cuando alcanza cierta generalidad, un imperativo que se dirige a todo el mundo se nos presenta, recíprocamente, en cierto modo, como una ley de la naturaleza". ${ }^{62}$ De esta manera, para Bergson la sociedad establece las reglas a través de la historia de modo que se nos presentan las obligaciones como si fueran fenómenos naturales; sin embargo, detrás de las apariencias fenomenológicas, es decir, en la esencia misma del fenómeno, se encuentra el secreto guardado universalmente. Ahí, en la esencia, nuestro autor ubica a la humanidad de la que

\footnotetext{
${ }^{60}$ Bergson, La evolución creadora, 84.

${ }^{61}$ Bergson, Las dos fuentes de la moral y la religión, 49.

${ }^{62}$ Bergson, Las dos fuentes de la moral y la religión, 52.
} 
trata de huir, la sociedad que se ha descubierto en el fondo de sí. Es ésta la causa por la que las leyes naturales de la ciencia se alimentan de observar y nutrir el orden social. Dichas leyes se parecen sin duda a las leyes naturales, pero están en otro grado y, sin embargo, son análogas a éstas.

Bergson nos presenta la sociedad como un "sistema de hábitos arraigados culturalmente" que responden de manera aceptable a una comunidad. Sin embargo, las leyes de la humanidad que mantienen el orden social no preceden a los hechos, sino que los hechos hacen que se formule una ley. Así, el imperativo moral social es capaz de reforzar las exigencias de la sociedad impartiendo castigos y es la religión la balanza de la justicia. "La religión, pues, acaba de llenar a nuestros ojos el espacio que hay, reducido ya por los hábitos del sentido común, entre un mandato de la sociedad y una ley de la naturaleza". ${ }^{63}$

Por lo tanto, el hábito de obedecer es la represión de la sociedad sobre la voluntad, lo que eleva o fetichiza los hábitos a mandatos de orden superior que nos obligan a creer y a exigir el sacrificio de la parte en una sociedad constituida por voluntades libres.

La esencia de la obediencia

"En vano se intentaría imaginar a un individuo desligado de toda vida social". 64 Para Bergson, la obligación no nos viene de fuera, no nos llega como coacción por un orden superior, sino que nos viene de adentro, de la conciencia. La conciencia se encuentra en lo profundo del ser, en la esencia; sin embargo, en la superficie la conciencia está en relación continua con otras personas, semejante y unida a ellas por una disciplina que es creada en una interdependencia recíproca, social. "Si el yo individual conserva vivo y presente el yo social, se conduce, aislado, como se conduciría con el estímulo y hasta con el apoyo de la sociedad entera". ${ }^{65}$

La adaptación del sujeto a la sociedad se realiza de manera pasiva ya que el sujeto es arrastrado al salir al mundo social y, más que cuestionar las obligaciones, muestra a la sociedad de manera acrítica lo que se espera de él; en suma, el sujeto cumple la ley del orden vigente.

Como ya hemos mencionado, en la visión de Bergson el orden vigente exige obediencia $y$, por lo tanto, este orden exige abandonarse a lo dado a priori,

\footnotetext{
63 Bergson, Las dos fuentes de la moral y la religión, 53.

${ }^{64}$ Bergson, Las dos fuentes de la moral y la religión, 55.

${ }^{65}$ Bergson, Las dos fuentes de la moral y la religión, 55 .
} 
abandonarse a lo "ya establecido" con anterioridad; sin embargo, la adaptación a la sociedad dada y las exigencias de sus leyes establecidas a lo largo de la historia desatan una guerra interna en el nivel subjetivo, por lo que la obediencia al orden vigente resulta en una resistencia en el propio sujeto; se genera una oposición a ser.

El sujeto en negativa a ser deposita su actuar no en la razón, sino que por medio del deseo y la pasión accede al poder ser, y sólo utiliza la razón para reprimir la acción. La esencia de la obligación del sujeto no es la razón, como pensaba Kant, sino algo totalmente distinto a ésta. Es en la voluntad donde Bergson fija su atención, y es desde ahí desde donde nos invita a buscar la representación esencial del hábito y lo complejo de una obligación.

Para resistir a la resistencia, para mantenernos en el camino recto cuando el deseo, la pasión o el interés nos desvían de él, debemos necesariamente darnos razones a nosotros mismos. Cuando hemos opuesto al deseo ilícito otro deseo, éste provocado por la voluntad, no ha podido surgir sino el llamamiento de una idea. En una palabra, un ser inteligente obra sobre sí mismo por medio de la inteligencia; pero de que se llegue a la obligación por vías racionales no se sigue que la obligación sea de orden racional. ${ }^{66}$

Instinto e inteligencia

"El veredicto de la conciencia es el mismo que daría el yo social". ${ }^{67}$ El imperativo categórico absoluto es de naturaleza instintiva o sonámbula, mientras que el imperativo categórico kantiano es sólo momentáneo. El imperativo categórico absoluto bergsoniano subsume en su dominio a la inteligencia momentánea sin buscar razones. "Nuestro pensamiento, en su forma puramente lógica, es incapaz de representarse la verdadera naturaleza de la vida, la significación profunda del momento evolutivo". 68

Lo dado, para Bergson, no da razones. Las leyes a priori son impuestas por la experiencia de la sociedad, mientras que el hábito adquirido por medio de la educación deriva de una imitación del instinto.

Así, el hábito de contraer hábitos tiene una forma comparable a la del instinto. A esta imitación del instinto Bergson la llama "el todo de la obligación", ya que la fuerza del hábito — por su intensidad y regularidad — es comparable al instinto.

\footnotetext{
${ }^{66}$ Bergson, Las dos fuentes de la moral y la religión, 60.

${ }^{67}$ Bergson, Las dos fuentes de la moral y la religión, 56.

${ }^{68}$ Bergson, La evolución creadora, 10.
} 
La imitación del instinto es llevada a cabo por un hombre de hábito, y el que mejor imite el hábito imita mejor el instinto. De esta manera Bergson va a distinguir la obligación puramente vivida, que sería el abandono, de la obligación plenamente vivida, que es la imitación del instinto. "Si queremos un caso de imperativo categórico puro, tendríamos que construirlo a priori, o por lo menos estilizar la experiencia". ${ }^{69}$

Por lo tanto, para Bergson, el instinto y la inteligencia son formas de conciencia que se han interpretado en el desarrollo de la vida humana para la sobrevivencia. El instinto y la inteligencia se utilizan con el fin de que proporcionen instrumentos destinados al trabajo. Así, la vida social encuentra su grado más alto en sociedades humanas al ofrecer un conjunto de reglas o leyes que son dadas por ser simplemente ya vividas. "Cuanto más nos elevamos en la escala de la generalización, más nos inclinamos, queramos o no, a atribuir a las leyes este carácter imperativo". ${ }^{70}$

\section{Sociedad cerrada y sociedad abierta}

"Todo se aclara si, por encima de estas manifestaciones, se va en busca de la vida misma". ${ }^{71}$ Con lo dicho anteriormente, Bergson nos muestra que la moral no se puede fundamentar en el culto a la razón, como lo hacían desde los filósofos griegos, hasta Kant y Hegel. La razón sólo es la conductora de la voluntad que nos impulsa a actuar. Es la razón, así, la que domestica nuestros impulsos vitales y nos conduce a una sociedad cerrada en la que los sujetos están ligados unos con respecto de los otros por obligaciones estrictas que no aceptan movimientos nuevos en el orden establecido hegemónicamente. "Antes de la moral, antes que la metafísica nueva, está la emoción, que se prolonga en impulso del lado de la voluntad y en representación explicativa del lado de la inteligencia". ${ }^{72}$

$42 \quad$ La sociedad cerrada y los deberes que ésta impone sobre la voluntad constituyen una disciplina que reprime el instinto social y que está en el fondo de la obligación social. Esta sociedad cerrada, en su desarrollo civilizado ha excluido y sigue excluyendo a través de la dictadura de la razón, haciéndonos creer que

\footnotetext{
${ }^{69}$ Bergson, Las dos fuentes de la moral y la religión, 62.

${ }^{70}$ Bergson, Las dos fuentes de la moral y la religión, 52.

${ }^{71}$ Bergson, Las dos fuentes de la moral y la religión, 124.

72 Bergson, Las dos fuentes de la moral y la religión, 81-82.
} 
el camino trazado es el que toda sociedad debe seguir. Esto no es más que una razón dogmática que por medio de la violencia ha instaurado la verdad. "Lo colectivo viene de este modo de reforzar lo singular, y la fórmula 'es el deber' triunfa de las vacilaciones que podríamos sentir ante un deber aislado". 73

La disciplina se instaura por la dominación y el dominado siempre es su enemigo. La disciplina, por lo tanto, es instaurada por una sociedad cerrada, totalizadora, mientras que, en una sociedad abierta, la sensibilidad aparece como acción distinta del hábito y el instinto falseando el "deber”, ya que la emoción exige dejar de razonar, de donde se desprende que la acción motivada por el sentimiento difiere de la obligación y se impone sobre la razón sin razonar el sentir.

\footnotetext{
"Presión social" e "impulso de amor" no son más que dos manifestaciones complementarias de la vida, normalmente aplicada a conservar en líneas generales la forma social que fue característica de la especie humana desde su origen, pero excepcionalmente capaz de transfigurarla, gracias a individuos cada uno de los cuales representa, como si se tratase de la aparición de una nueva especie, un esfuerzo de evolución creadora. ${ }^{74}$
}

La desobediencia es antinatural para la sociedad cerrada ya que rompe con el orden vigente establecido que ha sido construido por los humanos, por lo que la desobediencia es un impulso de creación que abre un horizonte hacia lo nuevo. Así, la construcción de un orden por lo humano es siempre aproximada, obtenida artificialmente. El orden vigente impuesto no es puro, de donde se deduce que todo orden establecido no es eterno, algo que la sociedad cerrada considera divino.

Si la sociedad se basta a sí misma, es la autoridad suprema. Pero si no es más que una de las determinaciones de la vida, se concibe que ésta, que ha debido depositar a la especie humana en tal o cual punto de su evolución, comunique na impulsión nueva a individualidades privilegiadas, que se fortalecerán con ella para ayudar a la sociedad a ir más lejos. ${ }^{75}$

\footnotetext{
73 Bergson, Las dos fuentes de la moral y la religión, 50.

74 Bergson, Las dos fuentes de la moral y la religión, 121.

75 Bergson, Las dos fuentes de la moral y la religión, 124.
} 
Coincidimos con Bergson en que quienes se rebelan para romper el orden establecido vigente son sujetos que están más allá de sí mismos y que alientan el sueño de transformación radical para formar sociedades nuevas y abiertas, excluidas de la sociedad cerrada.

\section{El principio de responsabilidad de Hans Jonas}

El avance científico

"El primer requisito de la utopía es la abundancia material para satisfacer las necesidades de todos; el segundo, la facilidad para obtener esa abundancia". ${ }^{76}$ Mucho se ha dicho en la historia de la filosofía que el ocio es el origen del filosofar; estar en la comodidad, con la satisfacción de la abundancia asegurada en bienes y la garantía de tener nuestras necesidades realizadas. De lo anterior se deduce que la abundancia es la llave que nos da acceso a la esencia formal de la utopía. Para Hans Jonas, al igual que para muchos pensadores, "el ocio significa precisamente la liberación de la esclavitud del trabajo", es el tiempo cero, donde se puede disfrutar de bienes y del amor al arte.

El avance científico-tecnológico redujo el tiempo de la elaboración de los productos, y las máquinas liberaron esfuerzo humano disminuyendo al esfuerzo mínimo la producción; sin embargo, la abundancia que se debería obtener sin esfuerzo no ha sido alcanzada por los operadores de las máquinas(los trabajadores). La ciencia, para Jonas, arrojó un desarrollo que aún sigue prometiendo avances radicales en un futuro indeterminado. La meta para la ciencia sería entonces "una más tolerable subsistencia de la actual población mundial”. Hasta hoy, lo que se ha demostrado es que el desarrollo técnico no ha satisfecho esta meta y lo único logrado han sido las "numerosas privaciones del planeta" porque, como se ha visto, la distribución social de los recursos — frutos de la naturaleza — no se ha llevado a cabo de una manera igual para todos. Así, el problema no se reduce sólo a lo natural-tecnológico, sino que también corresponde a lo económico-político. "Para conseguir metas más ambiciosas, aun cuando fueran preutópicas, más aún, para conseguir el status quo con la población creciente, es preciso hablar ya de un incremento de la producción global y de una técnica superior más agresiva". ${ }^{77}$

\footnotetext{
${ }^{76}$ Hans Jonas, El principio de responsabilidad (Barcelona: Herder, 1995), 300.

77 Jonas, El principio de responsabilidad, 301.
} 
La agresión a la naturaleza

"La cuestión no es en último término cuánto será capaz de hacer el hombre —en esto es lícito ser prometeico y dinámico-, sino cuánto de eso podrá soportar la naturaleza". ${ }^{78}$ Nuestro pensador ve en el avance científico la más grande amenaza para la naturaleza y, paradójicamente, se requiere mayor agresividad para conseguir una mejor calidad de vida para la subsistencia de la población actual. Pero falta ver la reacción, el comportamiento, la contestación de la naturaleza hacia esta agresión. El autor nos dice: "Para la naturaleza no supone diferencia alguna que el agresor provenga de la 'derecha' o de la 'izquierda', que la agresión sea marxista o liberal-burgués". ${ }^{79}$

La cuestión en último término para Jonas es: ¿cuánto podrá soportar la naturaleza a tanta agresión? Sin embargo, aunque el autor la toca muy ligeramente, otra pregunta que va en la misma línea debería interesar a la población que habita en la periferia de los centros hegemónicos: ¿cuánto es capaz de tolerar la naturaleza y un pueblo explotado injustamente?

Jonas menciona: "hoy en día nadie duda de que existan aquí límites de tolerancia", y el límite de la tolerancia está en relación con los "deseos humanos". Cuando estos deseos se vean afectados y causen efectos secundarios desventajosos, cuando se amenace de una manera irreversible la vida y se cargue de una manera unilateral el empuje, se aproximará una catástrofe para el equilibrio de los fines humanos. Esto sin duda representa un golpe a la idea de progreso, ya sea de la "fe" capitalista o de la socialista.

Los límites de la naturaleza

"El castigo acumulativo infligido a la naturaleza con las técnicas de maximización agraria empieza ya a dar muestras locales de sus progresivos efectos desastrosos". ${ }^{80}$ La cuestión fundamental para Jonas es tener claro hasta dónde llegan los límites de la naturaleza y qué tan cerca o lejos nos encontramos de estos límites. Un abordaje interdisciplinario podría responder a estos cuestionamientos. Nuestro autor nos propone una "ciencia medioambiental global”; así, en esta perspectiva, "el filósofo no dice nada más que escuchar".

\footnotetext{
78 Jonas, El principio de responsabilidad, 302.

79 Jonas, El principio de responsabilidad.

80 Jonas, El principio de responsabilidad, 304.
} 
La explotación desmedida de los recursos naturales y el uso excesivo de la energía nos han traído como consecuencia el incremento de la producción de calor, el sobrecalentamiento: "Es la inquebrantable ley de la entropía, que dice que con todo trabajo se 'pierde' energía, que toda energía acaba degenerando en calor y que el calor se dispersa, esto es que busca el equilibrio con el entorno". ${ }^{81}$ Pero el desarrollo y la energía producida no deben usarse con fines destructivos, sino pacíficos. Es decir, la energía se debe "utilizar con sabiduría y mesura, atendiendo a una responsabilidad global”. Para poner en práctica esta responsabilidad global se requiere una "nueva ciencia", que tendría que ver con la enorme complejidad de las interdependencias.

\section{El temor a la mortalidad}

"Sin duda el temor forma parte de la responsabilidad tanto como la esperanza". ${ }^{82}$ Por otro lado, la "cautela" es para nuestro autor un "mandamiento" de la responsabilidad, y mientras la ciencia no se ponga de acuerdo: "La inseguridad puede ser aquí nuestro destino permanente, lo cual tiene consecuencias morales". ${ }^{83}$

Estas amenazas a la vida humana causan temor e inseguridad en el ser humano sobre su porvenir, sobre el futuro incierto que se espera, que "no es todavía".

Lo que no "ha aparecido ya alguna vez" es la ontología del "no ser todavía"; es decir, en la utopía el hombre auténtico aún no "es todavía", sino que hace falta algo para llegar a ser. Se trata de un "deber alcanzar" para poder ser en la autodeterminación, y el ser humano, en el utopismo radical, no se ha alcanzado, pero como sueño sí.

Para Jonas, el "no ser todavía" es un inacabado, es precisamente la "frustración de las 'expectativas"', da una finitud; sin embargo, es a su vez una potencia a lo que jamás fue y jamás ha sido, y es esto lo que se opone a la mortalidad. Es la aparición de individuos siempre nuevos que siguen produciéndose, es futuro. Esta es la palabra clave en la ontología del "todavía no".

“Lo más elevado del pasado (lo más bajo no merece ser valorado sino como monumento a la vergüenza) es 'brillo anticipado de lo justo', que como tal aparece solamente en la mirada retrospectiva del futuro sin clases" ${ }^{84} \mathrm{En}$

\footnotetext{
81 Jonas, El principio de responsabilidad, 309.

82 Jonas, El principio de responsabilidad, 356

83 Jonas, El principio de responsabilidad, 310.

84 Jonas, El principio de responsabilidad, 345.
} 
síntesis, en su realización plena, en la contemplación como brillo, en el arte, en la experiencia estética. Para Jonas las obras de la cultura se tienen que mostrar como "camino ensayado y como contento de una esperanza sabida", pero tales instantes o experiencias estéticas, para nuestro autor: "Son un raro regalo y no deberíamos olvidar aquellos otros tormentos, a los que debemos más cosas aún (y algo distinto a una enseñanza acerca de un 'todavía-no')".85

Para Jonas, lo que hay que esperar —en un sentido contrario al "principio de esperanza"- es que todo contento produzca desencanto y es quizá esto lo único seguro que tenemos acerca del ser humano. "El problematismo humano es su propio fundamento, que lo sostiene. Tan importante es conducirlo 'hacia delante' hasta una claridad sin sombras, como hacia atrás hasta el aproblematicismo de la naturaleza animal". ${ }^{86}$

El deseo animal entra en contradicción con la verdad del ser porque es en lo humano donde encontramos esta síntesis. Es desde la historia del hombre en particular, y en la historia de la humanidad en general, desde donde debemos aprender y conocer los horrores y yerros para la esperanza. El "todavía no" se presenta como una sorpresa no agradable. Así, hay que resignarse a ser más modestos en nuestras metas con la naturaleza, ya que la naturaleza del ser humano no es unívoca.

Es absolutamente preciso liberar del sueño de la utopía la exigencia de la justicia, del bien y de la razón. Esa exigencia ha de ser cumplida por ella misma, sin pesimismo ni optimismo, sino de manera realista, sin la embriaguez de expectativas; sin pagar por tanto, ningún precio desmedido por ello, como en el caso de los monumentos quiliastas — 'totalitarios' - por naturaleza, dispuesto a sacrificar a los vivos en aras del porvenir. ${ }^{87}$

El principio de responsabilidad es hoy más necesario que nunca y se necesita "coraje para la responsabilidad". Esta responsabilidad es ese algo que nos obliga a actuar con "cautela" ante el temor por los atentados contra la naturaleza, temor que debe ser combatido en el deber de la acción y que, para Jonas, es el primer deber y va acompañado de esperanza.

\footnotetext{
85 Jonas, El principio de responsabilidad, 347.

86 Jonas, El principio de responsabilidad, 349.

87 Jonas, El principio de responsabilidad, 352.
} 


\title{
La vida negada en Enrique Dussel
}

La transmodernidad de la filosofía de la liberación

“Aparecen desde las propias entrañas del 'bien', del orden social vigente, un rostro, muchos rostros, que al borde de la muerte claman por la vida". ${ }^{88}$ En la filosofía dusseliana se estudia la modernidad desde la posición vivencial de las víctimas. Desde esta realidad ubicada geopolíticamente en la periferia de los centros hegemónicos, en su filosofía de la liberación Enrique Dussel realiza la crítica desde otra experiencia, desde una experiencia de exclusión y de negación al orden de vida de quienes decretan el imperativo del "bien".

La filosofía de la liberación es análoga a la africana y asiática, sumándose como un nuevo momento a la tradición mítica milenaria y presentándose como una nueva "racionalidad con pretensión de universalidad, y no como momento fideísta o irracionalista".

En la concepción mítica-simbólica de la filosofía de la liberación de Dussel no hay como principio un solo "Uno" totalitario y alienante, como en los primeros imperios de hierro, sino que hay muchos componentes originarios que no permiten encontrar una unidad primera porque, dada la concepción del origen del mundo (dependiendo ésta de la cultura en donde se nazca), se aprende a vivir.

\begin{abstract}
En efecto, desde Alaska hasta la Tierra del Fuego el universo es interpretado desde un principio "Dual”. No es ahora el "Uno" de Plotino o de Lao-Tsé, sino el "Dos" de los tlamatinime: el Ométeotl de los aztecas, la/el Alom-Qaholom (Madre-Padre) de los mayas, la/el Tocapo-Imaymana Viracocha de los amautas entre los incas, los "gemelos" de todas las culturas, desde los Grandes Lagos o praderas de Norteamérica hasta los caribes y Tupí-guaraníes o los alakaluf de la Patagonia austral. ${ }^{89}$
\end{abstract}

Para Dussel, la razón ético-crítica — propia de la filosofía de la liberación— se da con precisión filosófica "sólo cuando se ha consumado una escisión originaria". Esto es, una escisión entre el ser/pensar y la "realidad" como exterioridad positiva ante la ingenuidad de la identidad de lo "Uno". Así, la filosofía de la liberación que nace en la periferia adopta una actitud de rechazo a la modernidad en una época

\footnotetext{
${ }^{88}$ Dussel, Ética de la liberación..., 297.

${ }^{89}$ Dussel, Ética de la liberación..., 29-30.
} 
postmetafísica y postontológica, y avanza dentro de una nueva filosofía ética, metafísica y transmoderna.

\begin{abstract}
Siendo para nosotros la Modernidad un fenómeno mundial, ese contradiscurso, justamente él y no otro, pudo surgir en la razón crítica europea que se abría y se co-construía desde la Alteridad dominada, explotada: el Otro ocultado por la Europa dominante (que siempre pretenderá negar dicho contradiscurso). Pero ese contradiscurso europeo (europeo por su implantación geográfica) es fruto en el centroeuropeo también de la periferia-dominada..$^{90}$
\end{abstract}

\title{
El mal
}

"El sistema de eticidad (el 'bien') ahora se ha invertido en el 'mal', causa en las víctimas el dolor, sufrimiento, infelicidad, exclusión... muerte en algún nivel de sus existencias". ${ }^{11}$ Desde el bien perfecto y puro, se develan como evento real las víctimas no-intencionales; se presentan como "hecho empírico". Esta es la verdad del orden hegemónico vigente, que ya no es una verdad formal, sino un acaecer de la verdad fáctica en un "hecho empírico". Las víctimas que se rebelan desde más allá del ser del orden hegemónico vigente, lo hacen desde el horizonte del no-ser de ese orden. Las víctimas, entonces, padecen el ser del sistema vigente dado asumiéndolo como mentira. En otras palabras, para las víctimas, la verdad del orden establecido es la no-verdad, lo válido es no-válido, lo fáctico es noeficaz; por lo tanto, lo "bueno" es interpretado como lo "malo".

El "mal”, para la periferia de la que habla Dussel, es un momento negativo del ejercicio de la razón ética-crítica, por lo que surge una actitud crítica ante lo que domina, oprime, disciplina, aliena o mata.

Lo que asesina a las víctimas desde esta posición de exclusión es el "bien" del sistema de eticidad hegemónico vigente. Este "bien" es el que se nos ha enseñado y se nos presenta como algo ya "dado", por lo que este sistema que procede del pasado exige ser deconstruido para pasar a lo nuevo. Dussel, en su Ética de la liberación, va a de-construir el "bien" totalizador y maldito, que presenta como un proceso negativo, crítico para las víctimas que son asesinadas "no intencionalmente" por una institución que, en su doble cara, es perversa.

90 Dussel, Ética de la liberación..., 69.

${ }^{91}$ Dussel, Ética de la liberación..., 299. 
Esta es una ética de la vida. La negación de la vida humana es ahora nuestro tema. El punto de arranque fuerte, decisivo de toda la crítica y como hemos indicado, es la relación que se produce entre la negación de la corporalidad (Leiblichkeit), expresada en el sufrimiento de las víctimas, de los dominados (como obrero, indio, esclavo africano o explotado asiático del mundo colonial; como corporalidad femenina, raza no-blanca, generaciones futuras que sufrirán en su corporalidad la destrucción ecológica; como viejos sin destino en la sociedad de consumo, niños abandonados de la calle, inmigrantes refugiados extranjeros, etc.) y la toma de conciencia de dicha negatividad. ${ }^{22}$

\section{La crítica ética}

"Para la conciencia cómplice del sistema, las víctimas son un momento necesario, inevitable, un aspecto funcional o 'natural”" ${ }^{93}$ La Ética de la liberación va un paso adelante de las éticas formales o morales al ser crítica. Esta ética, en cuanto tal, implica que la víctima "puede juzgar críticamente la 'totalidad' de un sistema de eticidad" desde su realidad encarnizada, en el propio "hecho empírico" que se nos presenta en la realidad del sistema de eticidad vigente.

“El dolor de la corporalidad de las víctimas, como veremos, es exactamente el origen material (contenido) primero (equívoco ciertamente) de toda crítica ética posible". ${ }^{94}$ La crítica ética consiste, entonces, en "intentar situarse ante un sistema de eticidad empírico captado como totalidad, y pretender juzgarlo", es decir, tendríamos que situarnos en la alteridad del sistema dado, desde la perspectiva de las víctimas del sistema vigente de eticidad, y no como cómplices ingenuos.

La conciencia cómplice cree que las víctimas son un mal necesario. Sin embargo, para la conciencia crítica, las víctimas son el actor de la misma conciencia y están ubicadas en el mismo lugar de peligro que sufre el rehén. Las víctimas, para la razón ético-crítica de esta filosofía de la liberación, son sujetos éticos, seres humanos que no pueden producir, reproducir y desarrollar su vida, y que están condenados a la tierra desértica, árida, infértil.

Es así como la no-vida es un futuro de muerte en la vida; es "alienación" que deriva de la coacción del sistema de eticidad vigente que ha excluido la participación en la discusión, que ha silenciado los rostros afectados por alguna situación de muerte o que los ha asesinado para encubrir la verdad.

\footnotetext{
${ }_{92}$ Dussel, Ética de la liberación..., 309.

93 Dussel, Ética de la liberación..., 299.

${ }^{4}$ Dussel, Ética de la liberación..., 302.
} 
Frente al rostro de las víctimas aparece el "bien" del sistema de eticidad vigente invertido; sintetizando, el "bien" se presenta como lo "malo", es la inversión de los valores.

"La alteridad de las víctimas descubre como ilegítimo y perverso el sistema material de los valores, la cultura responsable del dolor injustamente sufrido por los oprimidos, el 'contenido', el 'bien”". ${ }^{95}$ La crítica ética descubre el sentido fuerte y realista del "mal” en la "totalización" del sistema. El juicio ético crítico invierte el sentido del "bien" y padece este "bien" como "mal", al cerrarse el sistema sobre sí, sin reconocer la alteridad y autonomía de las víctimas, cuando el sistema da muerte y no vida al negar posibilidades de reproducir la vida a las víctimas.

\footnotetext{
Las víctimas son re-conocidas como sujetos éticos, como seres humanos que no pueden reproducir o desarrollar su vida, que han sido excluidos de la participación en la discusión, que son afectados por alguna situación de muerte (en el nivel que fuera, y hay muchos y de diversas profundidad o dramatismo). ${ }^{96}$
}

Para Dussel, la razónético-crítica es el momento más desarrollado delaracionalidad humana porque subsume la razón material, suponiéndola y afirmándola, descubriendo la "dignidad" del sujeto y su imposibilidad de reproducir su vida, imposibilitado de vivir. Esta razón ética-crítica subsume también la razón formal y de factibilidad, ya que supone la defensa de la víctima advirtiendo su exclusión, además de poder interpretar las condiciones factibles del sistema vigente que imposibilitan la reproducción de la vida de las víctimas causando muerte.

La obligación de la "crítica" de la norma, acción, institución o sistema de eticidad (en parte o en totalidad) indica, exactamente, que el principio material universal de la ética no es sólo reproducción de la vida (como razón reproductora o pulsiones de felicidad del mismo tipo), sino también desarrollo de la vida humana en la historia (desde las pulsiones creadoras, que se arriesgan por el Otro a enfrentar al dolor y la muerte, y la razón crítica, que se torna escéptica de la no-verdad del sistema que genera víctimas). ${ }^{97}$

\footnotetext{
95 Dussel, Ética de la liberación..., 311-312.

${ }^{6}$ Dussel, Ética de la liberación... 299.

97 Dussel, Ética de la liberación..., 379.
} 
El "juicio material ético negativo" dusseliano es entonces posible, ya que afirma la vida desde el ámbito del sujeto humano como criterio y principio ético, además de afirmar la vida del sujeto desde la afirmación de su "dignidad", negándose como víctima. "[...] para que haya justicia, solidaridad, bondad ante las víctimas, es necesario 'criticar' el orden dado para que la imposibilidad de vivir de dichas víctimas se convierta en posibilidad de vivir y vivir mejor". $9^{8}$

Por lo tanto, el "juicio ético" de la "razón práctica crítica negativa" es transistemático, ya que procede de la realidad de la vida negada, apareciendo como un acontecimiento trans-ontológico en referencia a la totalidad ontológica de un sistema de eticidad dado.

El juicio que procede de las víctimas de lo real de la realidad está más allá del ser, está más allá de la metafísica, y aun de la ontología. Este no-ser que se ubica más allá es la posibilidad de la afirmación de la negación de la vida, es evidenciar la muerte y el asesinato de la vida de la víctima. Esta parte de la realidad es desvelada de su encubrimiento al afirmarse la vida en la alteridad en el Otro, como víctima oprimida de clase o excluida como pobre.

\section{Es una meta-teoría que se construye a través del análisis del ejercicio de la razón práctica crítica desde la praxis histórica de las víctimas y desde las filosofías críticas del siglo XIX y XX, la de los "grandes críticos", o las que podríamos llamar "filosofías malditas". 99}

Así, la ética de la liberación del filósofo Enrique Dussel intenta mostrar una teoría de la crítica ética.

La ética de la liberación o ética II

“Esta es una ética de la vida; ética crítica desde las víctimas". ${ }^{100}$ En la segunda parte del libro Ética de la liberación en la edad de la globalización y de la exclusión, Dussel desarrolla tres niveles de comprensión que ninguna ética anterior a ésta había analizado, por lo que se coloca en un nivel de mayor complejidad, más concreto y a la vez más radical.

Dussel presenta una serie de puntos que pueden variar de orden, pero con fin pedagógico nos muestra un intento de esquema:

\footnotetext{
${ }_{98}$ Dussel, Ética de la liberación..., 378.

99 Dussel, Ética de la liberación..., 300.

${ }^{100}$ Dussel, Ética de la liberación..., 495.
} 


\section{Primer nivel}

1. Se produce la negación originaria de las víctimas en su sentido fuerte. Es aquí donde el dolor se manifiesta; es el efecto real de la dominación o exclusión material y da inicio así la crítica ética.

2. Se afirma la ética radical de la vida negada de las víctimas, así como la expresión y el deseo de vivir.

3. Desde el reconocimiento de la víctima como el Otro que el sistema niega, descubre a la víctima con conciencia ética crítica a partir del dolor de la corporalidad.

4. Se enuncia el juicio ético-crítico negativo con respecto a la norma, que se descubre como el "mal” que causa muerte.

Segundo nivel

5. Las víctimas construyen sistémicamente una comunidad intersubjetiva que interpela crítica-negativamente a las mismas víctimas, para crear solidaridad y un deseo formal antihegemónico.

6. Se solidarizan en la crítica otros estratos sociales del sistema y se amplía así la comunidad, que adopta una nueva posición práctico-crítica ante el sistema.

7. Se teoriza sobre las causas de la negación de las víctimas del sistema al analizar dialécticamente y explicar científicamente; esto es la concientización.

8. Se construye con facticidad anticipada y se afirman alternativas posibles para la realización de un proyecto futuro, creando la utopía.

Tercer nivel

9. Deconstructivamente se rechazan en forma real y empírica las negaciones del sistema que causan víctimas y se llevan a la práctica acciones transformativas factibles éticamente.

10. Se construyen realmente, con criterios de factibilidad ética, nuevos momentos, instituciones, normas y acciones. En esto consiste estrictamente la praxis de liberación. 


\section{NEGACIÓN MATERIAL DE LA VIDA HUMANA, MUERTE DE LA VÍCTIMA. PUNTO DE PARTIDA RADICAL DE LA ÉTICA DE LA LIBERACIÓN}

¿Quién tiene que pedir perdón y quién puede otorgarlo? ¿Los que, durante años y años, se sentaron ante una mesa llena y se saciaron mientras con nosotros se sentaba la muerte, tan cotidiana, tan nuestra que acabamos por dejar de tenerle miedo? ¿Los que nos llenaron las bolsas y el alma de declaraciones y promesas? ¿Los muertos, nuestros muertos, tan mortalmente muertos de "muerte natural", es decir, de sarampión, tosferina, dengue, cólera, tifoidea, mononucleosis, tétanos, pulmonía, paludismo y otras lindezas gastrointestinales y pulmonares? ¿Nuestros muertos, tan mayoritariamente muertos, tan democráticamente muertos de pena porque nadie hacía nada, porque todos los muertos, nuestros muertos, se iban así nomás, sin que nadie llevara la cuenta, sin que nadie dijera, por fin, el “iYA BASTA!” que devolviera a estas muertes su sentido, sin que nadie pidiera a los muertos de siempre, nuestros muertos, que regresaran a morir otra vez pero ahora para vivir?

Subcomandante insurgente Marcos

\section{De la ética de la liberación a la política de la liberación}

Las éticas formales dejan fuera el contenido material de la ética al negar al sujeto corporal vivo, por lo que logran sólo un ámbito limitado de validez formal. Para la ética de la liberación, este ámbito es aceptable en países del centro hegemónico donde está garantizada la sobrevivencia. En los países periféricos, que constituyen el $85 \%$ de la humanidad en el planeta, se vive en un "estado de derecho" precario; es por este $85 \%$ de la humanidad que este filósofo mexicano descubre la necesidad de hacer una reflexión crítica desde la filosofía. Aquí, en la 
parte periférica, donde no existen garantías de sobrevivencia, se construye una ética crítica que reflexiona sobre la situación real de nuestra miseria.

El propósito de la ética, para Dussel, no es el acto "bueno" o "malo", como lo es para otras éticas, sino que ésta se ocupe de las condiciones universales de la norma, del acto y de la micro o macroestructura como institución. No hay decisiones buenas o malas, ya que ninguna acción que realizamos es perfecta porque siempre hay consecuencias "no intencionales"; entonces, ninguno de nuestros actos es bueno o malo, sino que tiene pretensión de bondad o no. Al realizar un acto con pretensión de bondad, el ser humano debe hacerse cargo de sus consecuencias "no intencionales" y corregir sus actos. Pero no porque nuestros actos generen efectos negativos no intencionales dejan de ser injustos, sino que niegan la injusticia cuando se corrigen los efectos previamente advertidos por nuestras acciones. Es por ello que la acción política fáctica con "pretensión política de justicia" está subsumida en la ética de la liberación, ya que puede y debe tener un horizonte posible normativamente en la lucha por la vida en comunidad.

La ética de la liberación reviste una problemática más compleja y tiene como contenido fundamental la necesidad de producir, reproducir y desarrollar la vida humana en comunidad; en última instancia, de toda la humanidad. Esto le da un carácter de universalidad.

La vida humana que hemos venido estudiando es el fundamento sobre el que se origina la argumentación de toda filosofía práctica. Así, el principio deóntico material fundamental de toda filosofía política posible es el deber político de producir, reproducir y desarrollar la vida de la humanidad, ya que el ciudadano es una corporalidad viviente.

\section{El principio crítico-democrático}

El estado de derecho es el sistema por el que los participantes con hegemonía pueden actuar legalmente. Éstos constituyen un estado de derecho que respeta un marco de instituciones; así, el sistema de derechos se convierte en un procedimiento formal de legitimidad.

El "principio democracia" es el momento discursivo del consenso, de la autonomía de la libertad y de la soberanía popular. Es la exigencia de una normatividad institucional moral-política que origina una libre participación simétrica de los ciudadanos. Estos niveles formales constituyen pretensiones de validez, pero toda decisión debe estar guiada por el contenido material de la ética, 
es decir, por la producción, la reproducción y el desarrollo de la vida humana en comunidad; en última instancia, de la totalidad de la humanidad. El ciudadano es miembro de una comunidad intersubjetiva de razón pública discursiva. La razón estratégica sitúa en específico los decretos de la decisión democrática de la comunidad discursiva, los ejerce y los transforma en facto. A su vez, esta razón estratégica debe ser responsable por los efectos negativos "no intencionales" de la acción política.

Los efectos "no intencionales" producen efectos criminales cuando se tornan intolerables para la vida humana; crean víctimas. La negación material de la vida humana es el punto de partida de la política ética crítica, y la víctima es el efecto crítico material. Los que no pueden cumplir con la ley del sistema hegemónico vigente son aquellos que han sido excluidos "no intencionalmente" y que el sistema de derecho vigente aún no puede incluir. Los excluidos son las víctimas que sufren las consecuencias perversas del sistema hegemónico de una minoría, y la ética y la política de la liberación se harán cargo de la voz crítica de las víctimas que sufren los efectos negativos de un sistema hegemónico perverso, agónico y decadente.

Los "sin derecho" luchan por el reconocimiento de nuevos derechos; este es un momento creador-histórico, innovador del cuerpo del derecho humano descubierto por las víctimas en la lucha por la liberación. Este descubrimiento es fruto de la conciencia crítica de quienes sufren los efectos negativos del antiguo estado de derecho, como las víctimas que, en su negatividad material, toman conciencia de que son sujetos sin derechos.

Para Dussel, los principios éticos definen la esfera de todos los principios prácticos-normativos en la lucha por la instauración de un nuevo orden que necesita ser determinado por los estratos más concretos.

El principio crítico-democrático parte de un consenso que se alcanza por la comunidad de los diferentes frentes de excluidos que constituyen un nuevo criterio de validez y de legitimidad contra la legalidad ingente y excluyente del sistema político en el poder; este principio declara legítimo lo hasta ahora ilegítimo. Es desde la negatividad material desde donde se descubre la negatividad "formal" o del derecho y se pasa a la esfera de la praxis con los nuevos movimientos sociales con pretensión de bondad.

\section{La política subsumida en la ética}

La reflexión incluida en este trabajo ha girado sobre la ética material dusseliana pensada desde los países periféricos — cuya población total constituye el 85\% 
de la humanidad en los primeros años del siglo XXI-, y a diez años de haberse levantado en armas el Ejército Zapatista de Liberación Nacional (EZLN).

La vida humana desde su origen ha sido un hecho natural "no problemático", pero en 1972 —al mostrarse los límites del crecimiento— la vida comenzó a ser un problema, no teórico, sino "angustiosamente ético".

En este sentido, el fundamento de toda la argumentación de Dussel es la vida y de ella parte su reflexión porque, aunque parezca algo de sentido común y obvio, la vida ha quedado olvidada en la filosofía política.

El contenido material de la ética incluye aspectos económicos, ecológicos y culturales, y se estudia para asegurar la continuidad de la vida humana. A partir de estos criterios, el principio deóntico material fundamental de toda filosofía política es posible, ya que para Dussel es un "deber", porque el ciudadano tiene una vida humana, ya sea como corporalidad viviente, como subjetividad necesaria o como sujeto autorreflexivo que tiene a cargo la responsabilidad de la vida.

Un sistema político pierde legitimidad cuando no permite que se reproduzca aceptablemente la vida humana de los ciudadanos. Es por esto por lo que se tienen que articular el aspecto material, el concepto de legitimidad y el "principio democrático" para enriquecer la concepción puramente formal o procedimental. Así, la razón política debe operar dentro de los parámetros establecidos por los principios de "vida" y "democracia" para producir, reproducir y desarrollar la vida humana en comunidad.

Cuando los efectos de la acción política son negativos, surgen otros tipos de desarrollo de la vida humana y brotan luchas por el reconocimiento de nuevos derechos; es ahí donde la segunda parte de la ética de la liberación, la parte deconstructiva, juega su papel más importante ya que exige acciones de mediano y largo plazo. Para Dussel, como ya hemos estudiado, sólo producen reflexión nueva los efectos negativos no-intencionales de algún sistema, ya que los efectos positivos confirman el acierto de las medidas tomadas.

La ética de la liberación realiza una crítica a las estructuras dominantes de cualquier sistema hegemónico vigente que produzca efectos negativos en lo económico, ecológico y cultural, o víctimas a su paso destructor. Esta filosofía nos advierte acerca de la necesidad de corregir los cauces de nuestras acciones.

La negatividad material de la vida de la víctima es el punto radical de partida de la ética de la liberación. La víctima, según se aprecia en la política de la liberación, es el ciudadano que injustamente es reprimido, negado o excluido del orden político vigente; se le niega la reproducción de su vida, se le niega la participación 
simétrica en la toma de decisiones, y lo excluyen hasta llevarlo a la ineficacia y conducirlo a la muerte.

La propuesta ética de Dussel da un paso adelante y transita hacia una política crítica que pretende transformar las patologías del Estado al poner en evidencia cómo se encubre a la víctima, desde la víctima misma. Cuando el sistema político hegemónico vigente produce víctimas en un número intolerable, dicho sistema nos dice que los miembros de la sociedad política sólo operan como mediaciones, que son reprimidos, disciplinados y alienados, y que su instinto de autoconservación se ha transformado hasta poner la vida de las víctimas en crisis porque no pueden producir, reproducir y desarrollar sus vidas.

El criterio radical fundamental de la filosofía crítica o de la liberación dusseliana es la vida de la víctima; asimismo, es el criterio de toda transformación política. Es por ello que los movimientos de la sociedad civil con pretensión de justicia renovada parten de una vida al borde de la muerte, marchan en crisis ejerciendo el micropoder y critican las estructuras del sistema político hegemónico vigente.

Las minorías marginales están constituidas por agentes de transformación ya que son miembros de una comunidad crítica antihegemónica que lucha por el reconocimiento de sus derechos en la sociedad civil. Este agente de transformación no es solipsista y meramente teórico, sino práctico y estratégico en posición crítica.

La praxis crítica de la comunidad de víctimas debe responder afirmativamente a la interpelación ética de las víctimas que se "autoliberan". La lucha por el reconocimiento de la "diferencia" es al mismo tiempo lucha por el desarrollo universal de la vida humana.

Para Dussel, la política de la liberación es una teoría de la estrategia de transformación revolucionaria, una filosofía práctica, una ética que desarrolla una política como "filosofía primera y práctica” y que analiza los criterios y principios que fundamenten la necesaria "transformación del mundo" desde sus víctimas.

Así, y sólo así, el que actúa bajo la responsabilidad por el Otro como "víctima" y cumple las exigencias éticas puede tener pretensiones de establecer un orden más justo. El acto de liberación es la respuesta efectiva a las exigencias de las víctimas, y lo innovador es el acto de liberación crítico-emancipatorio.

\section{La vida humana, la muerte y la sobrevivencia}

La reflexión ontológica se ocupa del fundamento de aquello que sustenta y que otorga el Ser, lo que abarca la totalidad de los entes como su ámbito propio. La 
ética de la liberación tiene un fundamento ontológico, pero sólo en la segunda parte, en la deconstrucción de lo ontológico, se comprende más claramente este fundamento superado. En esta segunda parte, el análisis de la estructura completa de su arquitectónica nos acerca a un sistema filosófico "no cerrado", sólo situando la problemática y transgrediendo la ontología.

La ontología política como filosofía primera en la ética de la liberación necesita un fundamento positivo último que le permita descubrir la voluntad y el poder político en su sentido verdadero, legítimo y fuerte, desde donde sea posible criticar las descripciones defectivas y reductivas del poder poniendo no la voluntad como el principio último, sino la vida y el "querer vivir" de la vida. De esta manera, el querer de la voluntad siempre es el "querer vivir" y se quiere este querer para poder vivir.

Desde la filosofía crítica de la liberación se esclarece un nuevo fundamento; ya no la "voluntad de poder", sino la "voluntad de vivir", donde la voluntad se juega como "voluntad de vida" y defectivamente como la parte negativa de la "voluntad de poder", ya que toda dominación es ejercida por la patología de la "voluntad de poder". La esencia del poder es la voluntad, y la esencia de la voluntad es la vida; entonces, la esencia del poder es la vida, siendo ésta la parte positiva de la "voluntad de poder".

El lugar de la voluntad es la corporalidad; la corporalidad es el ser viviente metafísico antropológico que es finito, vulnerable y necesitado, que siempre tiende a su inalcanzable realización. Esta pretensión de realización, en cuanto tal, es un fracaso desde el principio ya que intenta "no morir", "quiere permanecer en la vida". Este constante "permanecer en la vida" está inscrito en la esencia de la corporalidad humana.

Lo humano es lo que pone a los entes como mediaciones, como momentos para postergar su fracaso y para continuar prolongando su agónica existencia en su desesperada inalcanzabilidad de inmortalidad. La voluntad es exactamente el querer fundamental que puede, por ejemplo, colocar las mediaciones para demorar la siempre cercana muerte. Se trata de un impulso de vida inconsciente, ciego, irresistible e irrespetuoso de las leyes y normas establecidas, con la finalidad de conservar la vida y sobrevivir.

Para Dussel, los entes puestos por el poder no son entes sabidos (cognitivos), sino entes queridos (afectivos) prácticos, es decir, no son entes interpretables o comprendidos, ya que el "poder poner" al Otro como un ente sobre la voluntad de este Otro (dominación) es defectivo, pero el "poder-poner" como mediación para la permanencia, producción, reproducción y desarrollo de la vida da valor a 
los entes, los considera valiosos para la sobrevivencia. De esta suerte, el valor de los entes es puesto por el "querer" de la capacidad de vivir.

El ente valioso sólo vale para la sobrevivencia de la vida. Así, el que toma un ente como instrumento para no morir considera valioso al ente. La vida no es un instrumento; por lo tanto, no tiene valor porque es la fuente de la que se desprende todo valor; la vida tiene "dignidad" —que es más que el valor y va más allá de él一. Los entes sólo tienen valor como mediaciones para la conservación de la vida y sólo son valiosos para la sobrevivencia.

El poder político tiene como referencia una comunidad política que está construida por una diversidad de voluntades que se ligan intersubjetivamente a partir de la subjetividad de cada miembro y su carácter de actor social, a la vez que posibilita la unidad de las diferentes voluntades y la transformación hacia un mundo alterno.

Cada voluntad se anula mutuamente si estamos en constante lucha contra otras voluntades; la unidad intersubjetiva de las voluntades no se da en la constante guerra con los otros, sino con el "querer vivir dignamente" en comunidad, lo que se logra por un consenso racional en el que se unifica la fuerza haciéndola efectiva en una misma dirección para alcanzar un lenguaje metafísico común, en una comunidad de comunicación afectiva que sea capaz de instituir los medios políticos para la transformación de una comunidad en la cual se pueda producir, reproducir y desarrollar la vida para conservarla, para postergar la agonía y negar la muerte y para hacer justicia a la muerte de la "víctima". 


\section{Referencias bibliográficas}

Aristóteles. Ética nicomáquea, traducción de Julio Pallí Bonet. Madrid: Gredos, 1993.

Bergson, Henri. La evolución creadora. Madrid: Espasa-Calpe, 1973.

Bergson, Henri. Las dos fuentes de la moral y la religión. Buenos Aires: Sudamericana, 1962.

Cioran, Émile Michel. Breviario de podredumbre, traducción de Fernando Savater. Madrid: Punto de Lectura España, 2001.

Dussel, Enrique. El último Marx (1863-1882) y la liberación latinoamericana. México: Siglo XXI, 1990.

Dussel, Enrique. Ética de la liberación en la edad de la globalización y la exclusión. México: Trotta, 1998.

Dussel, Enrique. Filosofía de la liberación. México: Primero Editores, 2001.

Dussel, Enrique. Filosofía ética latinoamericana, tomo I. Presupuestos de una filosofía de la liberación. México: Edicol, 1977.

Dussel, Enrique. Filosofía ética latinoamericana, tomo II. Acceso hacia una filosofía de la liberación, México: Edicol, 1977.

Dussel, Enrique. Filosofía ética latinoamericana,tomo III. De la erótica a la pedagógica. México: Edicol, 1977.

Dussel, Enrique. Hacia un Marx desconocido. Un comentario de los manuscritos del 61-63. México: Siglo XXI, 1988.

Dussel, Enrique. Hacia una filosofía política crítica. Bilbao: Desclée Brouwer, 2001.

Dussel, Enrique. La producción teórica de Marx. Un comentario a los Grundrisse. México: Siglo XXI, 1985.

Dussel, Enrique. Las metáforas teológicas de Marx. Pamplona: Verbo Divino, 1993.

Dussel, Enrique. Método para una filosofía de la liberación. Superación analéctica de la dialéctica hegeliana. Guadalajara: Universidad de Guadalajara, 1991.

García Ruiz, Pedro Enrique. Filosofía de la liberación. Una aproximación al pensamiento de Enrique Dussel. México: Dríada, 2003.

Hegel, G.W.F. Enciclopedia de las ciencias filosóficas, traducción de Eduardo Ovejero y Maury. México: Casa Juan Pablos, 2002.

Heidegger, Martín. El ser y el tiempo, traducción de José Gaos. México: FCE, 2000.

Jonas, Hans. El principio de responsabilidad. Barcelona: Herder, 1995.

Kant, Immanuel. Filosofía de la historia, traducción de Eugenio Imaz. Bogotá: FCE, 1998.

Kant, Immanuel. Fundamentación de la metafísica de las costumbres, traducción de Luis Martínez de Velasco. Madrid: Espasa-Calpe, 1990.

Kant, Immanuel. Lecciones de ética, traducción de Roberto Rodríguez Aramayo y Concha Roldán Panadero. Barcelona: Crítica, 1998.

Lévinas, Emmanuel. Totalidad e infinito. Ensayo sobre la exterioridad, traducción de Daniel E. Guillot. Salamanca: Sígueme, 2002.

Martínez, José Luis. Nezahualcoyotl, vida y obra. México: FCE, 1996.

Nietzsche, Friedrich. La genealogía de la moral. Un escrito polémico. Madrid: Alianza Editorial, 1986. Rulfo, Juan. Los cuadernos de Juan Rulfo. México: Ediciones Era, 1994.

Sabato, Ernesto. Abbadón el Exterminador. Bogotá: La Oveja Negra y R.B.A, 1984. 

apuntes def sur es una colección de textos destinados a la divulgación del conocimiento académico entre un amplio público lector. Su enfoque temático abarca una diversidad de disciplinas relacionadas con el campo científico social y humanístico, por lo que tienen cabida en esta serie un conjunto misceláneo de ensayos, diarios de campo, informes intermedios de investigación académica, conferencias, correspondencia epistolar de relevancia histórica y otras aportaciones de significativa importancia que en igual medida despierten el interés del público conocedor y atraigan la atención de aquellos lectores que busquen introducirse o profundizar en el conocimiento de los temas y géneros expuestos.

Esta colección obedece al propósito de dar espacio a un número indeterminado de escritos que guardan en común, además de su calidad y relevancia pública, su breve extensión, característica que les confiere, potencialmente, una mayor vía de difusión bajo el formato de cuadernos. Apuntes del sur forma parte de la cobertura editorial amplia y plural que aspira a alcanzar el Centro de Estudios Superiores de México y Centroamérica (CESMECA) de la Universidad de Ciencias y Artes de Chiapas (UNICACH). 

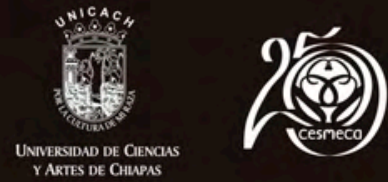

La ética de la liberación es capaz de ir desde el contenido material de la ética hasta más allá de los principios de las éticas formales, al profundizar en el análisis de la vida negada de las víctimas humanas de un sistema hegemónico vigente. Con ello se demuestra que la ética y la política no están separadas, sino que los principios de la ética de la liberación se pueden fundamentar en niveles más concretos, en una política de la liberación ética. 